\title{
CLASSIFICAÇÕES AMBIENTAIS PARA CONTROLAR A INTERAÇÃO GENÓTIPO x AMBIENTE COM APLICAÇÃO A CULTURA DO TRIGO (ত্titioum aestivum L.) NO RIO GRANDE DO SUL
}

ENEDINO CORREA DA SILVA

Engenhelro Agrônomo

Orientador: Prof. Dr. ROBERTO SIMIONATO MORAES

Tese apresentada à Escola Superior de Agricultura "Luiz de Queiroz"', da Universidade de São Paulo, para obtenção do título de Doutor em Agronomia. Área de Concentração: Estatística $\theta$ Experimentação Agronômica.

PIRACICABA

Estado de São Paulo - Brasil

Maio, 1981 
ii.

A meu pai (in memoriam)

DEDICO.

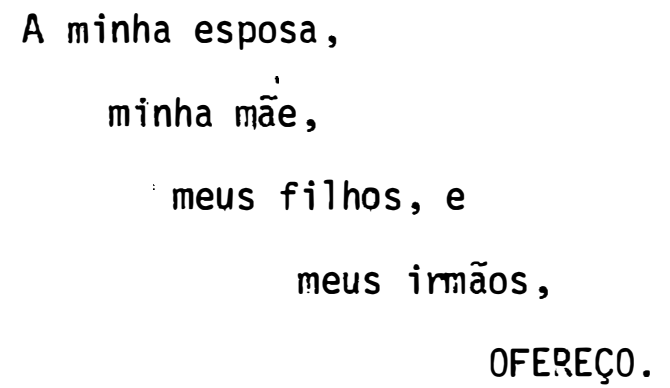


Ao Professor Dr. Roberto Simionato Moraes, pela orientação segura na realização deste trabalho.

A Empresa Brasileira de Pesquisa Agropecuāria (EMBRA PA), pela oportunidade oferecida para a realização do Curso de Esta tỉstica e Experimentação Agronômica;

Ao Centro Nacional de Pesquisa de Trigo (CNPT), pela cessão dos dados;

$\bar{A}$ colega Rosangela Segalla Afanasieff, pela colabora ção na elaboração dos programas de computador por nós utilizados;

Ao Professor Dr. Humberto de Campos, Coordenador do Curso de Pós-Graduação em Estatística e Experimentação Agronômica da ESALQ/USP e ao Professor Dr. João Gilberto Corrêa da Silva, Che fe do Departamento de Métodos Quantitativos da EMBRAPA, pelo apoio.

Aos colegas do Departamento de Métodos Quantitativos da EMBRAPA, pela solidariedade;

Aos Professores do Departamento de Matemática e Esta tỉstica da ESALQ, pela amizade;

Aos demais colegas do Curso de Pós-Graduação, pelo excelente convívio durante o Curso; 
Ao Professor Dr. Cássio Roberto de Melo Godoi, do De partamento de Matemática e Estatỉstica da ESALQ, pela versão do Resumo;

Aos funcionārios do Departamento de Matemātica e Estati̊stica da ESALQ: Maria Izalina Ferreira Alves, Rosa Maria Alves, Octâvio Frassetto e Maria Alayde Penteado de Souza, pela amizade e atenção dispensada:

A todos que, direta ou indiretamente, colaboraram pa ra a realização deste trabalho. 


\section{I $N$ N $D$ I}

Pàg.

RESUMO

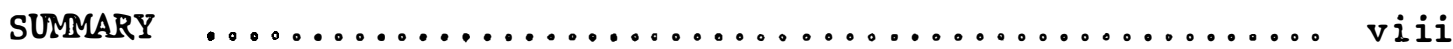

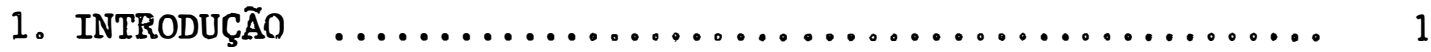

2. REVISÃO DE LITERATURA ......................... 5

3. MATERIAL E MÉTODOS ........................ 17

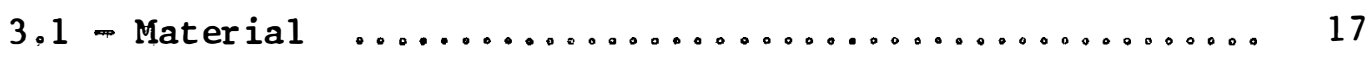

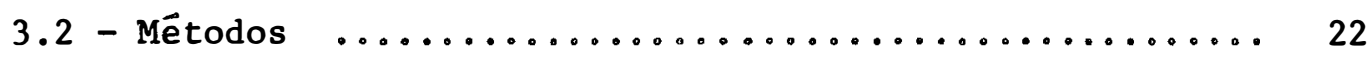

3.2 .1 - Estimativas de componentes de variância $\ldots .23$

3.2 .2 - Similaridade e classificação .......... 26

3.2.2.1 - Anālise de conglomeração $\ldots \ldots \ldots 28$

3.2.2.2 - Análise de componentes principais. 30

3.2.2.3 - Análise de variáveis canônicas ... 32

3.2 .3 - Análise de estabilidade ............... 34

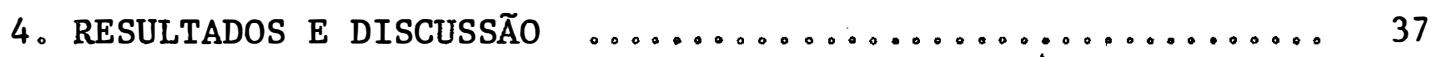

4.1 - Estimativas de Componentes de Variância ........ 37

4.2 - Classificação dos Locais ................. 45

4.2 .1 - Análise de conglomer ação ........... 45

4.2 .2 - Anālise de componentes principais ....... 48

4.2 .3 - Anālise de variāveis canônicas .......... 52

4.3 - Análise de Estabilidade ................. 56

5. CONCLUSÕES $\ldots \ldots \ldots \ldots \ldots \ldots \ldots \ldots \ldots \ldots \ldots \ldots \ldots \ldots$

6. LITERATURA CITADA ........................ 61

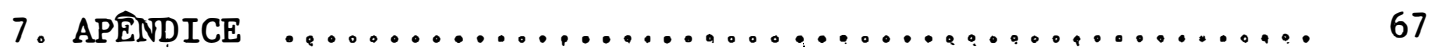


CLASSIFICAÇOES A.MBIENTAIS PARA CONTROLAR A INTERAÇAO GENOTIPO $\times$ AMBIENTE COM APLICAÇAO A CULTURA DO TRIGO (Triticum aestivum L.) NO RIO GRANDE DO SUL

Autor: $\quad$ ENEDINO CORREA DA SILVA

Orientador: $\quad$ Dr. Roberto Simionato Moraes

RE S U M O

A presença de interação genótipo x ambiente é o ponto crítico em pesquisas de melhoramento genético de plantas cultiva das, e a regionalização é uma das abordagens de caráter prático utí lizadas para o seu controle.

Utiliza-se, no presente trabalho, parte dos resultados do Ensaio Sul Brasileiro de Cultivares de Trigo Precoce referen te aos anos de 1975, 1976 e 1977 , na região mais produtora do Estado do Rio Grande do Sul, sendo a produção de grãos a variável escolhida para este estudo.

Inicialmente são obtidas estimativas dos componentes de variância objetivando um conhecimento da natureza das interações cultivar x ambiente. Em seguida, procede-se à classificação dos locais, procurando agrupā-los de acordo com a similaridade de seus pa 
vii.

drões de interação. São utilizados três métodos multivariados, sendo o primeiro o método de conglomeração, o qual utiliza como medida de similaridade um coeficiente de distância, o segundo é o método de componentes principais, o qual visa condensar em seus primeiros eixos a variabilidade existente. Esses métodos classificam os 1ocais dentro de cada ano em estudo. O terceiro é o método de variāveis canônicas, o qual leva em consideração as flutuações de ano pa ra ano nos efeitos da interação cultivar x local.

0 estudo da natureza das interações cultivar $\mathrm{x}$ ambiente indica alguma vantagem na separação dos locais nas três regiões da atual regionalização do Estado, e mostra também que as estimativas do componente de variância, $\sigma_{C L}^{2}$, a partir de dados de um único ano, são tendenciosas, devido à presença significativa das in terações cultivar $\mathrm{x}$ ano e cultivar $\mathrm{x}$ local $\mathrm{x}$ ano.

Assim, os métodos de análise de conglomeração e de anālise de componentes principais não apresentam consistência na classificação dos locais entre os anos estudados,' sendo o método de análise de variáveis canônicas aquele que melhor se adapta ao presente caso. Os resultados mostram que os locais das atuais regiões II, III e IV se comportam como uma única região no Estado, para a cultura do trigo. 
viii.

\section{CLASSIFICATIDNS DF ENVIRONMENTS TD CNNTROL GENOTYPES BY ENVIRONMENT INTERACTIONS WITH APPLICATION TO WHEAT (Triticum aestivum L.)}

IN RIO GPANDE DO SUL

Author:

Adviser :
ENEDINO CORREA DA SILVA

Dr. Roberto Simionato Moraes

\section{S U M IA A R Y}

The presence of genotype $\mathrm{x}$ environment interaction is the critical point in genetic improvement of cultivated plants, and regionalization is one of practical approach used for its control. Part of results of "Ensaio Sul Brasileiro de Cultivares de Trigo Precoce" from 1975, 1976 and 1977 years are used in this work, concerning the most productive region of Riio Grande do Sul Sta te, being the grain weight variate selected for this study.

To begin with, variance components are obtained to find the nature of cultivar $x$ environments interaction. Following, locals classification is presented, taking interaction standards si milarities as bases of grouping. Three multivariate methods are applied: clustering, using distance measures as basis; principal components method, designed to reduce dimensionality of existent varia 
ix.

bility: these methods classify locals within each year of study; the third method is of cannonical variates, which takes in consideration year by year fluctuation in cultivar $\mathrm{x}$ local interaction.

The nature of cultivar $\mathrm{x}$ environments interaction shows some advantages in separating locals in the three regions actually existent in the State, showing also biasedness in $\sigma_{\mathrm{CL}}^{2}$ estimates when data from one year is used, due to the presence of cultivar $x$ year and cultivar $\mathrm{x}$ local $\mathrm{x}$ year interaction.

Clustering and principal components methods showed no consistency in locals classification during the period of years considered. Cannonical variates method was considered the best appropria te for the present case. Results derived from data showed that II, III and IV regions did not differ significantly, being considered just one region. 
O Rio Grande do Sul possui caracterîsticas de clima e solo bastante vạriadas. Estudos de localização de ocorrência das variāveis climáticas permitiram dividir o Estado em nove regiões tritícolas. As cultivares de trigo precoce recomendadas para o Rio Grande do Sul possuem características agronômicas variadas, sugerin do alterações de comportamento quando semeadas em condições ambientais diferentes. Estes fatos são usados como argumento para que, na recomendação de cultivares, se passe a considerar mais o comportamento específico de uma cultivar em determinada região tritỉcola do que o comportamento geral da cultivar em todas as regiões do Estado, Vários métodos têm sido propostos para a análise estatística de interações em geral, e de interações genötipo x ambien te em particular. E necessārio primeiro saber se a interação está 
presente, e então considerar sua importância e efeito no trabalho subsequente.

Para o melhorista, o problema resulta da deficiência de cultivares ou genótipos manterem um padrão consistente de desempenho quando cultivados sob uma gama de ambientes variáveis no tempo e/ou no espaço. Isto significa que a precisão das comparações fí ca reduzida, desde que para um dado conjunto de ambientes ò componente da interação torna-se parte do erro experimental, e como ócom ponente torna-se grande, fica muito difícil identificar um simples destaque para o referido conjunto de ambientes. Assim, se requer cer tas modificações a introduzir no programa de melhoramento usado, sen do desaconselhável a recomendação de uma única cultivar para uma am pla extensão de ambientes, na base do comportamento médio, jà que não otimiza o desempenho dos genótipos.

Entre os métodos propostos para o estudo das interações genótipo $\mathrm{x}$ ambiente, segundo um enfoque mais direto, existem uns voltados para definição de "regiões de adaptação", ou seja, para regionalização de locais, e outros para o estudo da estabilidade de cultivares. Destas duas estratégias, a primeira poderä ser de grande utilidade para controle da interação cultivar x local, que está associada às variaçöes ambientais predizỉveis. A eficiência da regionalização, quando realizada dentro de cada ano em estudo, será tanto maior quanto mais alta for a proporção das interações cultivar $x$ ambiente que seja devida a local. Uma regionalização que leve 
em consideração as variações ambientais prediziveis e não predizíveis, ou seja, que considere as flutuações de ano para ano nos efei tos da interação cultivar x local, ainda pouco foi pesquisada.

0 modelo matemático para descrever o fenótipo resultante de um genótipo quando sujeito a um dado ambiente é apresentado, em sua forma mais geral, como segue

$$
Y_{i j}=\mu+G_{i}+A_{j}+(G A)_{i, j}
$$

onde $Y_{i j}$ é a resposta esperada do i-ésimo genótipo no j-ésimo ambiente, expresso em termos de uma média geral da população; $\mu$; efeito do i-ésimo genótipo, $G_{i}$ : efeito do j-ésimo ambiente, $A_{j}$; e efei to da interação genótipo $x$ ambiente para o i-ésimo genótipo no j-és mo ambiente, (GA) ${ }_{i j}$.

Assim, componentes de variância podem ser usados para separar os efeitos de genótipos, ambientes e sua interação. Equa cionando os quadrados médios observados nas análises de variância em suas esperanças no modelo misto, obtêm-se as estimativas dos componentes de variância que proporcionam um conhecimento da naturezadas interações cultivar $x$ ambiente, e são utilizadas no presente traba1ho.

O estudo de regionalização de locais é realizado, com parando três métodos multivariados, os quais procuram agrupá-los de acordo com a similaridade de seus padrões de interação cultivar x lo cal. 
O primeiro é o método de conglomeração, o qual utili za como medida de similaridade um coeficiente de distância. o segun do é o método de componentes principais, o qual visa condensar em seus primeiros eixos a variabilidade existente. Esses dois métodos classificam os locais dentro de cada ano em estudo. 0 terceiro $\vec{e}$ o método de variāveis canônicas, o qual leva em consideração as flutuações de ano para ano nos efeitos da interação cultivar x local. Finalmente, tem sido feito um estudo de estabilidade das cultivares sobre as combinações de locais e anos, considerando, na equação $(1 \circ a)$, uma regressão de $(G A)_{i j}$ em $I_{j}$, ou seja

$$
\text { (GA) }_{i j}=\beta_{i} I_{j}+\delta_{i j},
$$

onde $\beta_{i}$ é um coeficiente de regressão linear para o i-ésimo genótipo, e $\delta_{i j}$ um desvio. $I_{j} \bar{e}$ o indice de ambiente, obtido atravēs da média de todas as cultivares no j-êsimo ambiente, subtraỉda da média geral. Usando $(1 . a)$ e $(1 . b)$, estuda-se o modelo

$$
Y_{i j}=\mu+G_{i}+\left(1+\gamma_{i}\right) I_{j}+\delta_{i j}
$$

O propósito do presente trabalho é, através da mẹtodologia exposta, verificar a adequação da regionalização existente, e oferecer subsidios para o seu aprimoramento. 
5.

\section{REVISATO DE LITERATURA}

Na bibliografia consultada encontram-se referências a vários métodos de controle da interação genōtipo x ambiente. De um modo geral, pode-se agrupar os métodos em duas 1 inhas gerais de tratamento do problema. Uma delas se fundamenta na regionalização de locais e outra no estudo da estabilidade de cultivares. Dentro da primeira linha existem dois aspectos: um que se'fundamenta principalmente nas características ambientais, procurando ajustar as necessidades da cultura às disponibilidades ambientais existentes, es pecialmente no que se refere a clima e solo: o outro parte das reações das cultivares quando expostas às diversas condições ambientais, procurando caracterizar regiões homogêneas, quanto ao comportamento relativo das cultivares.

0 processo de regionalização visa o agrupamento de 
locais de uma área geográfica em sub-āreas de modo a se obter uma redução da magnitude das interações cultivar x local. Assim, parece lógico que se procure dividir a ärea em sub-äreas, tendo como base as características de temperatura, precipitação e tipos de solo, de modo a minimizar a interação cultivar $\mathrm{x}$ local. Seguindo este prime ro aspecto, PASCALE e MOTA (1966) estudam as caracterỉsticas climáticas do Rio Grande do Sul e determinam os tipos agfoclimáticos para a cultura do trigo naquele Estado, correlacionando, ulteriormente, as disponibilidades agroclimäticas com as necessidades bioclimā ticas das cultivares utilizadas pelos agricultores. Eles trabalham com resultados de experimentos realizados em Buenos Aires e Pelotas, utilizando 15 cultivares brasileiras e argentinas bioclimaticamente conhecidas, com semeaduras quinzenais entre abril e outubro de 1960. Fund amentam-se na comparação, em ambos os locais, do comportamento dessas cultivares para determinar as necessidades bioclimáticas das cultivares brasileiras.

MOTA et alii (1974) apresentam uma proposta de regio nalização agroclimatológica do Estado do Rio Grande do Sul para värias culturas, utilizando como critērio básico as aptidões climáticas das culturas, definidas com base em suas exigências e cotejadas com as disponibilidades climáticas das regiões. O método considera apenas os fatores climáticos, sendo tal restrição justificada, segundo os autores, pela incapacidade desses fatores serem controlados em uma exploração agrỉcola, como podem sê-lo os caracteres eda- 
fológicos.

Ainda na primeira linha de tratamento, agora conside rando o segundo aspecto, SILVA et alii (1963), estudando a interação de cultivares de milho em localidades do Estado de São Paulo, constatam que a influência do solo mostra-se mais importante do que o efeito das variações climáticas de um para outro ano, com relação à variabilidade de produção.

ALLARD e BRADSHAW (1964) classificam as variações am bientais em dois tipos, a saber, prediziveis e não predizíveis. Os autores procuram caracterizar cada um destes tipos de variação e su gerem controles diferentes para cada uma delas. As implicações de efeitos significativos da interação cultivar $\mathrm{x}$ ano são consideradas pelos autores como muito diferentes daquelas referentes à interação cultivar x local, isto porque as variações de ano para ano não são prediziveis, e o melhorista, para controlā-las, deve buscar a obten ção de cultivares também adaptadas a flutuações ambientais não predizíveis, sem as quais o processo de regionalização não é efetivo. HORNER e FREY (1957) propõem a subdivisão do Estado de Iowa em regiões homogêneas que possibilita uma adequada recomendação regional de variedades de aveia, utilizando um procedimento para a redução da interação cultivar $\mathrm{x}$ local dentro de cada região. Eles geram distintos agrupamentos de locais para cada uma das subdi visões do Estado em 2, 3, 4 e 5 regiões, utilizando resultados de experimentos efetuados em 9 locais durante 5 anos, com poucas varie 
dades comuns a todos os anos. Para cada uma dessas quatro classes de subdivisões é obtido o quadrado médio da interação cultivar x local dentro da região para os agrupamentos resultantes das subdivisões mais coerentes do ponto de vista de proximidade geogräfica. Para ca da classe de subdivisão estas estatỉsticas são arranjadas em uma tabela de dupla entrada, segundo anos e agrupamentos de locais.Eles utilizam o teste de Tippet para comparar, para cada classe de subdi visão, o agrupamento com média mais baixa de quadrados médios' para os 5 anos com aquele do Estado como um todo. Concluem que aquele é significativamente mais baixo do que o último. 0 melhor agrupamento de locais para cada uma das regionalizações em 2, 3, 4 e 5 regiões reduz o quadrado médio de $11 \%, 21 \%, 30 \%$ e $40 \%$, respectivamente, em relação ao quadrado médio do Estado.

LIANG et alii (1966) obtêm estimativas dos vārios com ponentes da interação cultivar $x$ ambiente em ensaios de cultivares de trigo, aveia e cevada realizados durante três anos no Estado de Kansas. Os autores constatam a presença de componentes de variância da interação cultivar x local significativos para o trigo e a cevada, e propõem a divisão daquele Estado em sub-regiões de cultivo pạ ra cada uma destas espécies, independentemente. o critério usado pa ra gerar as diversas possibilidades de regionalização é a distribui ção de chuvas e as normais de temperatura no Estado durante 30 anos. Os autores testam o quadrado médio da interação cultivar x local em cada classe de regionalização com o quadrado médio da corresponden- 
te interação de segunda ordem cultivar x local x ano. Eles obtêm ra zoável redução da interação cultivar x local, mas sem qualquer consistência sobre a interação de segunda ordem.

SCHLEHUBER et alii (1970) e MOREIRA et alii (1971) calculam coeficientes de correlação entre a produção de cultivares de trigo, ensaiadas em diferentes locais do Estado do Rio Grande do Sul. De 70 coeficientes de correlação possíveis, apenas 25 são esta tisticamente significativos e, apesar disto, os autores dizem que certas cultivares mostram-se superioras em muitos locais estudados. oSóRIO et alii (1974) estudam a adaptação regional das cultivares de trigo precoce no Rio Grande do Sul, utilizando da dos do Ensaio SA-IPEAS de Cultivares de Trigo Precoce, em 1968 e do Ensaio Sul Brasileiro de Cultivares de Trigo Precoce, em 1969 e 1970. 0 estudo foi realizado considerando a atual regionalização daquele Estado (MOTA et alii, 1974). Para estudar o desempenho das cultivares (considerando as produções médias de anos) em duas épocas de se meadura nas diversas regiões, foi utilizado o téste sugerido por COCHRAN e COX (1957), que consiste em estruturar os efeitos do quadrado médio de cultivares, do quadrado médio das interações cultivar $x$ região, cultivar $x$ época e cultivar $x$ região $x$ época num teste $F$ para cultivares. Comparações mültiplas entre cultivares são realizadas, e os autores concluem que, com poucas exceções, as cultivares que mais se destacaram por seu comportamento médio no Estado são também as mais produtivas em cada região triticola, dispensando o critério regional para as cultivares estudadas. 
ROSITO (1974) trabalha com o Ensaio Sul Brasileiro de Cultivares de Trigo Precoce e Tardio nos anos de 1969 a 1971, no Es tado do Rio Grande do Sul. 0 autor busca avaliar a magnitude da interação cultivar x local para as āreas tritícolas do Estado e a ade quação da regionalização existente através das interações e correla ções entre as cultivares, de um local para outro, investigando a pos sibilidade de modificação da regionalização existente. 0 autor conclui que a regionalização existente no Estado apresenta um razoável grau de compatibilidade com relação à interação cultivar x local.

Entre os processos multivariados aparece o de ABOU-EL-FITTOUH et alii (1969), utilizando a análise de conglomeração ("cluster analysis") para classificar locais, usando resultados de experimentos de competição de cultivares de algodão durante o perío do de 1960 a 1964 na Região da Cultura do Algodão dos Estados Unidos. Eles também adotam como critério a redução da interação cultivar x local, e é o primeiro da bibliografia consultada que utiliza Classificação Numérica em estudos de regionalização. Trabalham, ini cialmente, com uma matriz de estimativa de efeito da interação cultivar x local para cada um dos dois ciclos da cultura do algodão es tudados. A partir de cada uma dessas matrizes são obtidas duas medi das de similaridade entre todos os possiveis pares de locais. Estas similaridades são um coeficiente de distância e um coeficiente de correlação. Eles concluem que a medida de similaridade que se mostra mais adequada é o coeficiente de distância, utilizando como crí 
tério de escolha entre as duas medidas a soma de quadrados da interação cultivar x local dentro de grupos de locais para equivalentes estágios do processo de conglomeração.

Os autores utilizam, também, para classificar locais, o método de componentes principais, envolvendo quatro cultivares co muns no estudo. Encontram $92 \%$ da variabilidade condensada nos dois primeiros eixos, e os utilizam para detectar possíveis conglomerados.

BYTH et alii (1976) utilizam procedimento de análise de conglomeração e ordenação para anālise de um grupo de experimentos internacionais do Centro Internacional de Melhoramento de Milho e Trigo (CIMMYT). Os dados correspondem a produção de 49 cultivares de trigo, escolhidos entre os mais cultivados no mundo, obtidos de: experimentos efetuados em 63 locais situados em extensa área de cul tivo no período 1967-1968. O método é estendido para fazer uma dupla classificação: de locais e de cultivares.

CAMPBELL e LAFEVER (1977) adotam método de conglomeração para agrupar e estudar as similaridades de 9 locais de exper $\underline{\mathbf{i}}$ mentos de trigo no leste dos Estados Unidos a partir da produção mé dia de 11 cultivares em 3 anos. Utilizam como medida de similaridade o coeficiente de correlação entre as produções médias dos 3 anos de todos os possiveis pares de locais.

CORDEIRO (1978) aplica o método de conglomeração, do modo utilizado por ABOU-EL-FITTOUH et ali $i$ (1969). As similaridades 
são um coeficiente de distância. O autor efetua anālises preliminares para comparação de resultados dos métodos de máxima distância, centrōide e ligação média, métọ̣os que aglomeram as entidadas a serem classificadas uma a uma, e adota o método da ligação média por se mostrar mais estável e oferecer melhores recursos para interpretação. O autor trabalha com dados do Ensaio Nacional de Milho na Re gião Centro-Sul do Brasil nos anos agrícolas de 1974/75, 1975/76 e $1976 / 77$.

FREEMAN (1973) diz haver vārios métodos para calcular similaridades, e isso pode afetar a conglomeração obtida, ao analisar o trabalho de ABOU-EL-FITTOUH et alii (1969).

SEIF et alii (1979) apresentam um procedimento multi variado para classificar locais, utilizando análise canônica. Os au tores trabalham com 9 cultivares de trigo em 11 locais da região trí tỉcola da Austrālia, e sugerem a subdivisão da mesma em 2 sub-regiões.

Considerando a linha que estuda a estabilidade de cul turas, aparece inicialmente o trabalho de YATES e COCHRAN (1938), o qual sugere a decomposição da interação cultivar $\mathrm{x}$ ambiente. Para ca da cultivar determina-se a regressão linear da produção em relação à média de produção de todas as cultivares em cada ambiente. Uma equação de regressão é ajustada para cada cultivar. Essa equação, re presentada em um grä́fico de eixos cartesianos, mostra o comportamen to individual de cada cultivar sob o efeito dos diferentes ambientes. Os autores usam essa equação para fazer previsões. 
O procedimento de YATES e COCHRAN (1938) tem sido a base para vārios autores no desenvolvimento de métodos que estimam parâmetros para a determinação da estabilidade de produção de culti vares.

WRICKE (1962) define um parâmetro de estabilidade que denomina de ecovalência (valência ecológica). A ecovalência è uma medida de avaliação das oscilações de rendimentos sob variadas condições de ambiente. A soma de quadrados da interação cultivar $x$ ambiente è dividida nas partes atribuíveis às cultivares isoladas. A associação entre médias de produção e ecovalência é avaliada através do coeficiente de correlação de Spearman.

FINLAY e WILKINSON (1963) usam uma anālise de adaptạ ção de cultivares em ensaio com 277 cultivares de cevada em sete am bientes. Os autores trabalham com os dados transformados para a escala logaritmica e sugerem que cultivares com baixo coeficiente de regressão são consideradas como estáveis.

EBERHART e RUSSEL (1966) usam um coeficiente de regressão $\beta_{i}$ como uma primeira medida de estabilidade, mas vão além e consideram a soma de quadrados dos desvios $\mathrm{s}_{\mathrm{di}}^{2}$ como uma segunda medida. 0 uso de dois parâmetros de estabilidade pode ser avaliado por JOWETT (1972), usando dados de sorgo, e encontra que a ecovalên cia de WRICKE (1962) é menos informativa que os dois parânetros de EBERHART e RUSSEL (1966). Esses usam um indice de ambiente e consi$\operatorname{deram} \beta_{i}$ o coeficiente de regressão da produção sobre o indice de 
ambiente para a i-ésima cultivar. Eles sugerem que um cultivar dese jado deveria ter alta média, coeficiente de regressão $\left(\beta_{i}\right)$ igual a 1,0 e variância devida ao desvio da regressão tão pequena quanto pos sivel $\left(s_{d i}^{2}=0\right)$.

SHUKLA (1972) tambêm faz a partição da soma de quadrados da interação cultivar x ambiente em componentes para cada cul tivar separadamente, considerando a "variância de estabilidade" $\sigma_{i}^{2}$ do i-ésimo cultivar, definido como a variância sobre ambientes de $\left(^{(G A)_{i j}}+\bar{e}_{i j}\right.$ na equação (1.a), onde $\bar{e}_{i j} \bar{e}$ a média de $e_{i j k}$ sobre repetições, considerando $\underline{k}$ repetições. 0 autor encontra uma estimativa imparcial de $\sigma_{i}^{2}$ e um critério aproximado para testar se $\sigma_{i}^{2}$ é gran de a ponto de considerar a cultivar não estável.

$$
\text { TAI (1971) usa } \alpha_{i} \text { como uma medida de estabilidade, a }
$$
qual mede a resposta linear da i-ésima cultivar aos efeitos ambientais, e também define uma segunda medida $\lambda_{i}$. Se o componente de variância para o desvio da linearidade para a i-ésima cultivar é $\sigma_{\text {st }}^{2}$ e a variância do erro ē $\sigma_{e}^{2}$, então

$$
\lambda_{i}=\frac{\sigma_{s t}^{2}+\sigma_{e}^{2}}{\sigma_{e}^{2}}
$$

0 autor mostra que o termo (quadrado médio do desvio x número de repetições/quadrado médio do erro) é maior do que a estimativa de $\lambda_{i}$ quando existem mais cultivares que ambientes. 0 autor salienta que o melhorista ficarā satisfeito com a obtenção de nỉveis médios de estabilidade. Os valores $\left(\alpha_{i}=0, \lambda_{i}=1\right)$ são refe 
ridos como estabilidade média, e os valores $\left(\alpha_{i}=-1, \lambda_{i}=1\right)$ como perfeita estabilidade.

TAI (1975), usando o conceito de desenvolvimento sequencial dos componentes de produção, apresenta um método de anālise da interação cultivar $x$ ambiente, baseado no método de anālise de caminho ("path analysis") desenvolvido por WRIGHT (1921, 1934). TAI (1979) apresenta os resultados das anālises de interação cultivar $x$ ambiente usando dois métodos de análise de estabilidade e a anālise de caminho ("path analysis"). Foram escolhidos três tipos, utilizando um (SHUKLA, 1972), dois (TAI, 1971), e três (TAI, 1975) parâmetros de medida da contribuição genotîpica na interação cultivar $\mathbf{x}$ ambiente. 0 autor quando usa dois parâmetros, $\alpha_{i}$ e $\lambda_{i}$, segue a metodologia de EBERHART e RUSSEL (1966), só que mostra uma outra maneira de testar os parâmetros. Conclui que a variância de estabilidade $\sigma_{i}^{2}$ de SHUKLA (1972) mediu aproximadamente o mesmo que o segundo parâmetro de estabilidade $\lambda_{i}$.

PARODA e HAYES (1971) enfatizam que a regressão 1inear de EBERHART e RUSSEL (1966) seria simplesmente uma medida da resposta de uma cultivar particular, enquanto o desvio da regressão $\left(s_{d}^{2}\right)$ pode ser considerado como uma medida de estabilidade; cultivares com menor desvio são de natureza mais estáveis. Isto confirma o que concluem BREESE (1969) e SAMUEL et alii (1970).

OLIVEIRA (1976) compara seis métodos de determinação de desempenho em plantas cultivadas, analisando a estabilidade de 
cultivares. 0 autor conclui que os métodos de FINLAY e WILKINSON (1963) e de EBERHART e RUSSEL (1966) foram mais informativos do que os demais. 
17.

\section{MATERIAL E METODOS}

\section{1 - Material}

Os dados utilizados são parte dos resultados do Ensaio Sul Brasileiro de Cultivares de Trigo Precoce A (ESBCTP) nos anos agrícolas de 1975, 1976 e 1977, efetuado sob a coordenação do Centro Nacional de Pesquisa de Trigo, da Empresa Brasileira de Pesquisa Agropecuāria (EMBRAPA), e executado, no perỉodo acima referido, pelas seguintes instituições:

- Centro Nacional de Pesquisa de Trigo - EMBRAPA;

- Secretaria de Agricultura do Rio Grande do Sul;

- Faculdade de Agronomia e Veterinäria da Universidade do Rio Grande do Sul;

- Federação das Cooperativas de Trigo - FECOTRIGO; 
- IPB - Comércio de Sementes:

- Faculdade de Agronomia da Universidade Federal de Pelotas.

Neste ensaio o território do Estado do Rio Grande do Sul é dividido em nove regiões trititolas (MOTA et alii, 1974). Os locais de teste variam de ano para ano e são sj.tuados em elevada pro porção nas Regiões II, III e IV (Figura 1).

No presente trabalho consideram-se apenas as regiões II, III e IV, as mais produtoras do Estado.

No ano de 1975,31 cultivares são utilizadas em cada um dos 8 locais das Regiões II, III e IV, todas comuns a todos os locais. No ano de 1976, 28 cultivares são utilizadas em cada um de 8 locais, sendo todas comuns a todos os locais. No ano de 1977, 20 cultivares são utilizadas em cada um de 7 locais, todas comuns a to dos os locais.

O delineamento experimental usado é blocos casualiza dos com 3 repetições (os experimentos com 4 repetições tiveram a $4^{\text {a }}$. repetição eliminada).

As cultivares ensaiadas nos três anos nas 9 regiões são relacionadas na Tabela 1. Essa relação é a mesma ao considerar-se as 3 regiões mais produtoras. Essa tabela permite observar a grande variação na escolha de cultivares entre anos de cultivo. 


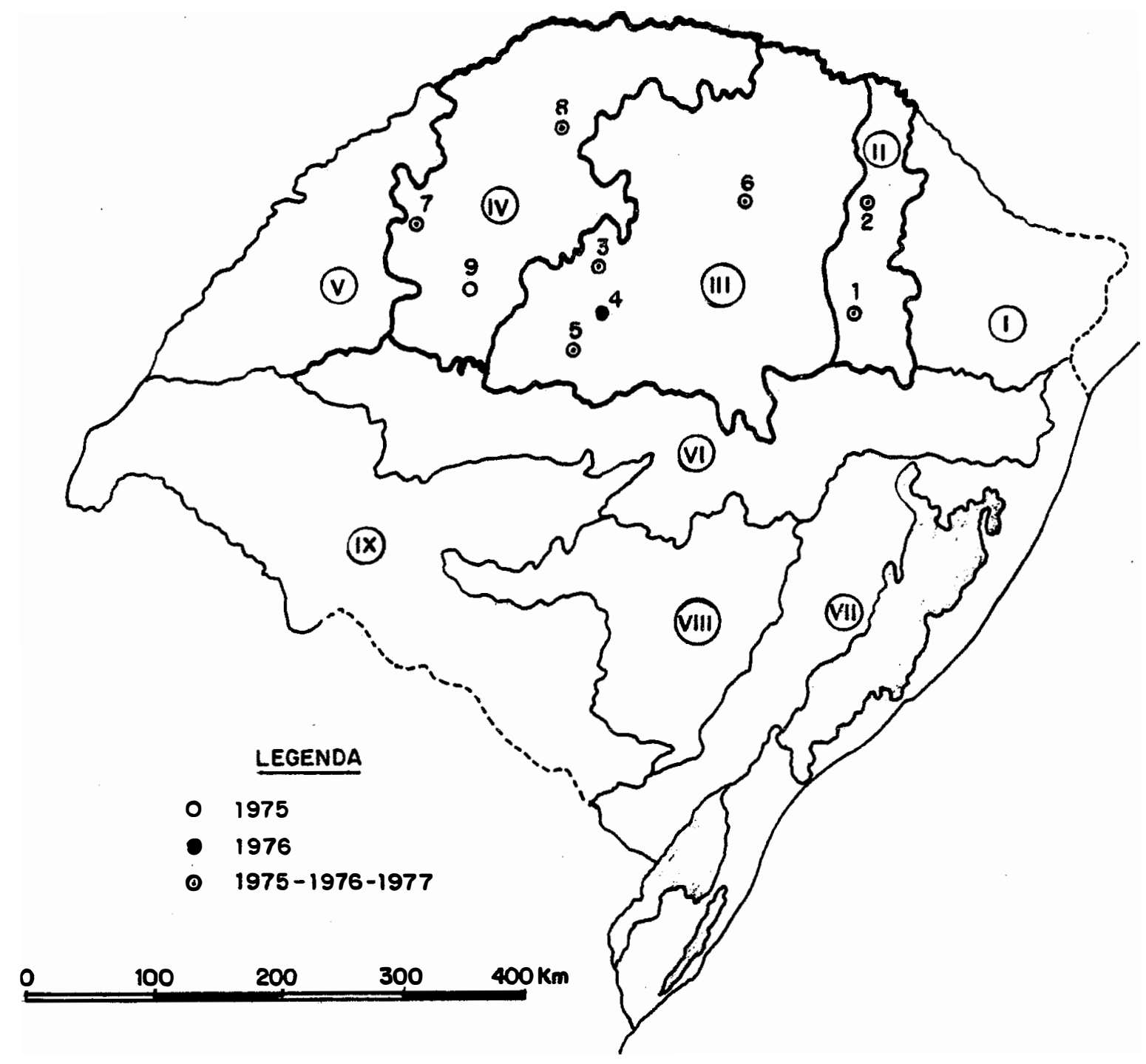

Figura 1 - Distribuição dos experimentos do ESBCTP nas três regiões tritícolas mais produtoras do Rio Grande do Sul nos anos de 1975,1976 e 1977. 


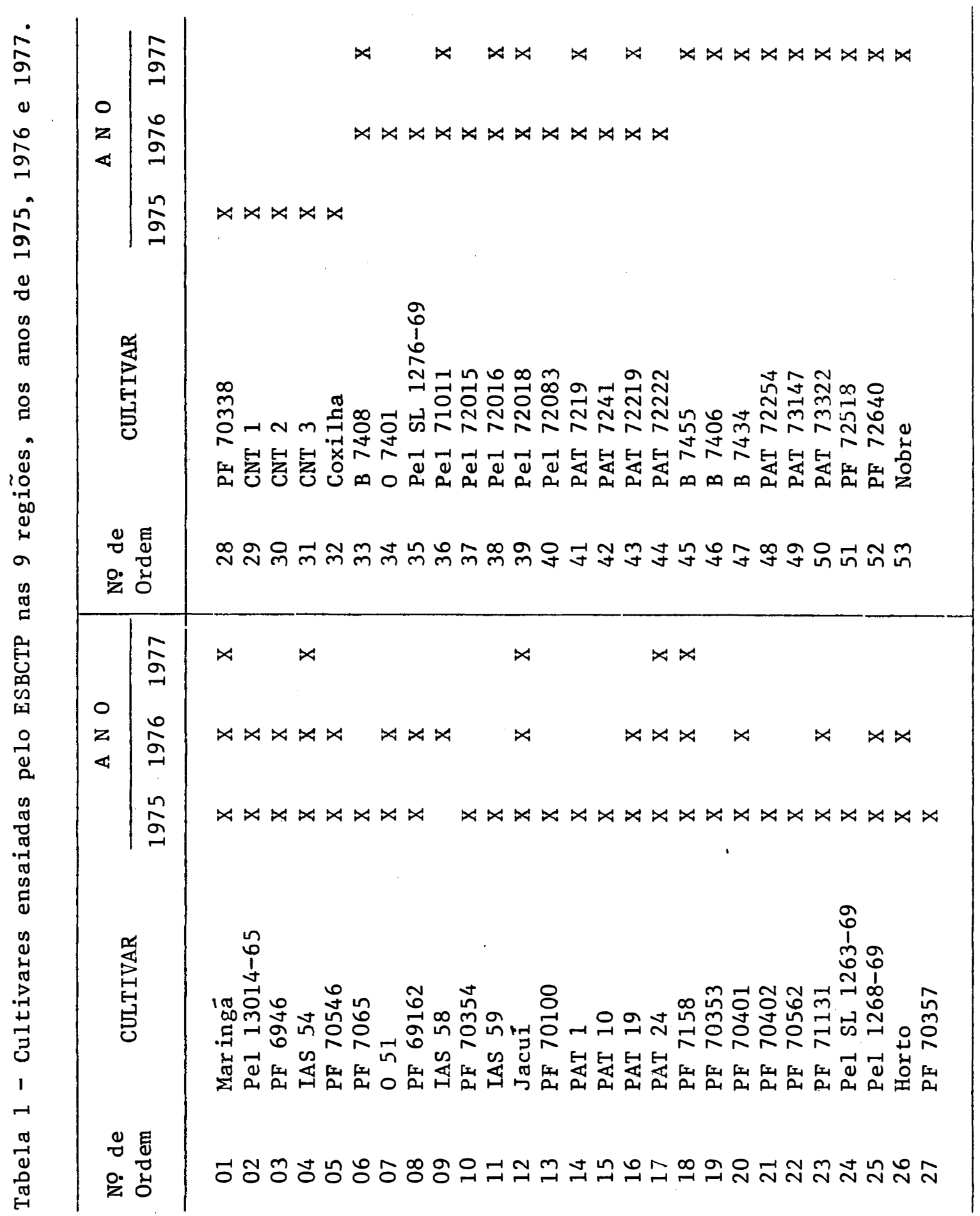


A Tabela 2 apresenta a relação dos locais onde foram instalados os experimentos do Ensaio Sul Brasileiro de Cultivares de Trigo Precoce A em cada uma das três regiões nos anos de 1975, 1976 e 1977.

Tabela 2 - Locais dos experimentos do ESBCTP nos anos de 1975, 1976 e 1977, nas regiões II, III e IV.

\begin{tabular}{|c|c|c|c|c|c|}
\hline \multirow{2}{*}{ REGIÃO } & \multirow{2}{*}{ No } & \multirow{2}{*}{$\mathrm{L} O \mathrm{CA} \mathrm{AL}$} & \multicolumn{3}{|c|}{$\mathrm{A} \mathrm{NO}$} \\
\hline & & & 1.975 & 1976 & 1977 \\
\hline \multirow{2}{*}{ II } & 1 & Veranópolis & $\mathrm{x}$ & $\mathrm{x}$ & $\mathrm{x}$ \\
\hline & 2 & Lagoa Vermelha & $\mathrm{x}$ & $\mathrm{X}$ & $\mathrm{X}$ \\
\hline \multirow{4}{*}{ III } & 3 & Cruz Alta & $\mathrm{x}$ & $\mathrm{X}$ & $\mathrm{x}$ \\
\hline & 4 & Es pumoso & & $\mathrm{x}$ & \\
\hline & 5 & Jūlio de Castilhos & $\mathrm{x}$ & $\mathrm{X}$ & $\mathrm{X}$ \\
\hline & 6 & Passo Fundo & $\mathrm{x}$ & $\mathrm{X}$ & $\mathrm{X}$ \\
\hline \multirow{3}{*}{ IV } & 7 & São Luiz Gonzaga & $\mathrm{x}$ & $\mathrm{X}$ & $\mathrm{X}$ \\
\hline & 8 & Santo Augusto & $\mathrm{x}$ & $\mathrm{x}$ & $\mathrm{X}$ \\
\hline & 9 & Santo Ângelo & $\mathrm{x}$ & & \\
\hline
\end{tabular}


Cada parcela é constituỉda de cinco fileiras de 5 me tros de comprimento, espaçadas de $0,2 \mathrm{~m}$, sendo tomadas apenas as 3 fileiras centrais como úteis.

A densidade de semeadura $\vec{e}$ de 300 sementes aptas por $\mathrm{m}^{2}$. As recomendações para adubação de solo ficam a critērio do örgão executor, de acordo com as exigências da ārea escolhida.

Os ensaios são tratados somente com inseticidas, não se utilizando tratamento com fungicidas.

Na colheita, os seguintes dados, dentre outros, são indicados para serem tomados sobre cada parcela:

- peso do hectolitro;

- peso de mil sementes;

- produção de grãos em gramas/parcela de $3 \mathrm{~m}^{2}$.

Dentre essas variāveis indicadas para anālise dos resultados, a variável resposta escolhida para este trabalho é peso dos grãos, em quilogramas/ha.

\section{2 - Métodos}

Interações significativas cultivar $\mathrm{x}$ ambiente sugerem que um programa de melhoramento deve ser orientado para o desenvolvi mento de cultivares particularmente adaptadas a ambientes especiais. 
Assim, programas experimentais procuram estudar o com portamento de cultivares em diversos locais, escolhidos de modo a obter-se uma razoāvel representatividade da ārea em estudo. Além dis so, os experimentos têm que se estender por um número suficiente de anos que permita uma representatividade da variabilidade de clima e suas influências ao longo dos anos.

\subsection{1 - Estimativas de componentes de variāncia}

Observações de experimentos repetidos sobre anos e locais, com estes agrupados em regiões, podem ser descritas pelo mo delo

$$
\begin{aligned}
\mathrm{Y}_{i j m k(r)=\mu} & +A_{m}+R_{r}+(A R)_{m r}+L_{k(r)}+(A L)_{m k(r)}+ \\
& +B_{j m k(r)}+C_{i}+(C A)_{i m}+(C R)_{i r}+ \\
& +{ }^{(C A R)_{i m r}}+(C L)_{i k(r)}+(C A L)_{i m k(r)}+ \\
& +e_{i j m k(r)}
\end{aligned}
$$

onde:

$$
\begin{aligned}
\mathrm{Y}_{i j m k(r)=} & \text { resposta da i-ésima cultivar na j-ésima repetição } \\
& \text { no m-és imo ano do k-ésimo local dentro da r-ésima } \\
& \text { região; } \\
\mu= & \text { média geral; } \\
A_{m}= & \text { efeito do m-ésimo ano, } m=1, \ldots, a ; \\
R_{r}= & \text { efeito da r-ésima região, } r=1, \ldots, g ;
\end{aligned}
$$




$$
\begin{aligned}
L_{k(r)}= & \text { efeito do } k \text {-ésimo local dentro da r-ésima região, } \\
& k=1, \ldots, l_{r} ; \\
B_{j m k(r)}= & \text { efeito da j-ésima repetição no k-ésimo local den- } \\
& \text { tro da r-ésima região no m-ésimo ano, } j=1, \ldots, d_{m k(r)} ; \\
C_{i}= & \text { efeito da i-êsima cultivar, } i=1, \ldots, v ; \\
e_{i j m k(r)}= & \text { erro aleatório em } Y_{i j m k(r)} \cdot \\
& \text { Os efeitos representados por combinações de letras }
\end{aligned}
$$
maiúsculas são interações entre os respectivos fatores que elas designam. Com exceção aos efeitos de cultivar e região, todos os demais são considerados aleatōrios, sendo ${ }^{(C R)}$ ir, por definição,

Inicialmente, é efetuada a análise individual de cada experimento, com o objetivo de obter a estimativa da variância do erro de cada um. Ulteriormente, anālises de variância são efetua das sobre ambientes combinados de quatro modos:

1) análises conjuntas dos locais dentro de cada ano em cada re gião da atual regionalização (II, III e IV);

2) anālises conjuntas de locais dentro de regiões, para cada ano:

3) análises conjuntas de todos os locais em cada ano, ignorando regiões;

4) análise conjunta de locais e anos, ignorando regiões. 
0 modelo para cada uma das anālises consideradas pode ser obtido por uma simplificação do modelo (3.2.1.a), redefinindo-se as populações de referência para os efeitos e adaptando-se os valores dos subscritos $\underline{m}$ e $\underline{r}$. As anälises são realizadas segundo es quema de análise de variância apropriada (COCHRAN e COX, 1957; KEMP THORNE, 1975).

As análises conjuntas identificadas como 1,2 e 3 utilizam os dados correspondentes às cultivares comuns em cada caso. Assim, as análises conjuntas de locais dentro de cada combinação de ano e região utilizam 31 cultivares em 1975, 28 cultivares em 1976 e 20 cultivares em 1977; as análises conjuntas de locais dentro de regiões em cada ano, e de todos os locais em cada ano utilizam também 31,28 e 20 cultivares, respectivamente, para os anos de 1975, 1976 e 1977. A análise conjunta de locais e anos, ignorando regiões, utiliza as 5 cultivares e os 7 locais, comuns aos 3 anos.

$\mathrm{Na}$ anālise conjunta sobre anos utilizam-se combinações apropriadas de somas de quadrados para teste de efeito de cultivares. O número de graus de liberdade apropriado é obtido usando o pro cedimento sugerido por SATTERTHWAITE (in PIMENTEL GOMES, 1976).

Estimativas de $\sigma_{e}^{2},{ }_{C}^{2}, \theta_{C R}^{2}, \sigma_{C L(R)}^{2}, \sigma_{C L}^{2}$ e $\sigma_{C L A}^{2}$ são obtidas para as diversas anālises conjuntas efetuadas. As estimativas desses componentes de variância são obtidas igualando-se os qua drados médios das fontes de variação aos correspondentes valores es perados e resolvendo-se o sistema para os componentes de variância. 
Comparações entre estas estimativas indicam a importância relativa dos diferentes componentes de interação e oferecem informações sobre a natureza das interações cultivar $x$ ambiente. A heterogeneidade do erro produz tendenciosidade sobre as estimativas destes compo nentes, particularmente quando o número de repetições varia entre os experimentos. ABOU-EL-FITTOUH e RAWLINGS (1967) apresentam expressões adequadas para a correção dessa tendenciosidade. No caso estudado por aqueles autores, eles não adotam essa correção, por julgarem a tendenciosidade resultante da heterogeneidade de variância, desprezível em comparação com os erros padrões das estimativas dos componentes de variância. Como no presente caso o número de repetições é ó mesmo em todos os locais, esta tendenciosidade poderá ser ignorada.

\subsection{2 - Similaridade e classificação}

0 problema de medir. similaridade entre uma coleção de entidades,e classificá-las em grupos a partir de um conjunto de crí térios, tem sido estudado por muitos pesquisadores.

Esse tipo de problema tem sido encontrado frequentemente em vários campos da pesquisa. Vários métodos têm sido propostos para a avaliação numérica de afinidades ou similaridades entre entidades e para a ordenação destas em grupos a partir daquelas. SNEATH e SOKAL (1973) apresentam detalhada exposição de todas as for 
mas de anālise numérica usadas em taxonomia para resolver problemas de similaridade e classificação de entidades.

Valores estimados do efeito da interação cultivar $x$ x local são obtidos, para cada ano, a partir da análise conjunta 3 , provenientes da expressão

$$
\begin{aligned}
& \quad(\mathrm{CL})_{i k}=Y_{i k}-\bar{Y}_{i,}-\bar{Y}_{. k}+\bar{Y}_{.}, \\
& \sum_{i=1}^{v}(\mathrm{CL})_{i k}=0 \quad, \quad \sum_{k=1}^{\ell}(\hat{C L})_{i k}=0 .
\end{aligned}
$$

Estes são os valores estimados do efeito aleatōrio (CL) ${ }_{i k}$, obtidos quando restrições são impostas ao modelo

$$
Y_{i k}=\mu+C_{i}+L_{k}+(C L)_{i k}+\bar{e}_{i k}
$$

forma restrita do modelo geral (3.2.1.a), para o caso de um ano e uma região.

Estes valores podem ser dispostos em matrizes de dimensão $\ell \times \mathrm{v}$, onde $\underline{\mathrm{v}} \overline{\mathrm{e}}$ o nümero de cultivares comuns aos $\ell$ locais. Para medir as similaridades entre locais, cada local é representado por um vetor de valores estimados da interação culti var $x$ local, constituindo o conjunto desses vetores a mațriz de valores estimados do efeito da interação cultivar x local, referenciadas anteriormente. Uma linha tipica desta matriz tem a forma

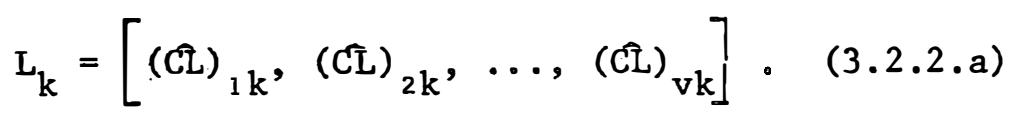


Neste estudo são utilizados métodos de classificação numérica para verificar se existem entre os locais estudados padrões de interação similares em relação às cultivares utilizadas.

\subsubsection{1 - Anāi ise de conglomeração}

A medida de similaridade entre quaisquer dois pontos (entidades) $k, k^{\prime}, \bar{e}$ definida como a distância média entre esses pon tos em um espaço de $\underline{v}$ dimensões, tendo como expressão

$$
\mathrm{d}_{\mathrm{k} \mathrm{k}^{\prime}}^{2}=\Delta_{\mathrm{kk}^{\prime}}^{2} / \mathrm{v}
$$

onde,

$$
\Delta_{k k^{\prime}}=\left\{\sum_{i=1}^{v}\left[(C L)_{i k}-(C \hat{C L})_{i k^{\prime}}\right]^{2}\right\}^{1 / 2} .
$$

Esta medida $\Delta_{k k^{\prime}}$ foi primeiramente definida para clas sificação numérica por SOKAL (1961). Contudo, o uso de distância co mo uma medida de similaridade taxonômica é apresentado por MAHALANO BIS (1936), introduzindo conceito de distância generalizada.

Desde que $A_{k k^{\prime}}$ cresce com o nümero de caracteres (cul tivares no caso em estudo), a distância média $d_{k k^{\prime}}^{2} \bar{e}$ mais comumente utilizada (SNEATH e SOKAL, 1973).

A utilização de $d_{k k^{\prime}}^{2}$ no presente estudo justifica-se pelo fato de que $d_{k k^{\prime}}^{2}$ é uma medida de uso muito comum em taxonomia,e estā estritamente relacionada à soma de quadrados da interação cultivar x local. Mostra-se, facilmente, que $\frac{v}{2} d_{k k^{\prime}}^{2} \bar{e}$ a soma de quadrados da interação dentro de uma região formada pela combinação dos 
locais $k$ e $\mathrm{k}^{\prime}$.

Estas distâncias são computadas para todos os possíveis pares de locais, para cada uma das matrizes de interação culti var x local correspondentes às anālises de interesse.

Adota-se como procedimento de conglomeração um método do grupo dos aglomerativos, sequenciais, hierārquicos, sem super posição, que são os mais frequentemente empregados para classificação de material biológico (SNEATH e SOKAL, 1973).

Entre os métodos que aglomeram as entidades a serem classificadas uma a uma, o adotado é o da ligação média, o qual se mostra mais estāvel e oferece melhores recursos para interpretação (CORDEIRO, 1978). Esse método ē originalmente estabelecido por soKAL e MICHENER (1958) e é descrito por SNEATH e SOKAL (1973).

0 método trabalha sobre a matriz de similaridades e aglomera, em seu primeiro estāgio, as duas entidades mais similares (de menor distância média). A distância deste novo caso aos demais pode ser obtida pela estratégia combinatorial de' Lance e Williams (SNEATH e SOKAL, 1973), sendo que o processo continua até que todos os casos estejam em um único grupo. As anālises são efetuadas utili zando-se o sistema de programas CLUSTAN (WISHART, 1978). As saỉdas das anālises são feitas em dendogramas utilizando como escala o coe ficiente de distância correspondente aos grupos formados em cada ci clo do processo. 


\subsubsection{2 - Anălise de componentes principais}

Um outro método para avaliar e descrever relações de similaridade entre entidades é o método de componentes principais.

o objetivo deste método é produzir uma série de variāveis hipotéticas 1 inearmente transformadas, denominadas "componentes principais" das variáveis originais. As novas variáveis são mutuamente independentes e podem, então, ser consideradas separadamente. Elas têm uma ordem decrescente de variabilidade tal que so mente os primeiros componentes podem ser necessārios para condensar a informação contida nas variāveis originais. Os detalhes desse método foram descritos por SEAL (1964) e MORRISON (1976), e somente um resumo é apresentado. A transformação linear requerida para computar os componentes principais pode ser escrita como:

$$
\mathrm{y}=\mathrm{xA},
$$

onde $\underline{\mathrm{y}} \overline{\mathrm{e}} \mathrm{o}$ vetor $(1 \mathrm{x} v \mathrm{v})$ dos $\underline{\mathrm{v}}$ componentes principais de um dado lo cal, $\underline{x}$ é o vetor $(1 \times$ v) dos efeitos da interação para as $\underline{v}$ cultiva res nesse local, como visto em (3.2.2.a), e $\mathrm{A} e \bar{a}$ matriz ( $\mathrm{x}$ x v) dos coeficientes, usada na transformação, tal que $\mathrm{AA}^{\prime}=I=\mathrm{A}^{\prime} \mathrm{A}$.

A matriz de variâncias e covariâncias das variáveis transformadas é dada por $Z=A^{\prime} S A$, onde $S$ é a matriz de variâncias e covariâncias das cultivares. A matriz $\mathrm{Z}$ é uma matriz diagonal, uma vez que as variáveis transformadas não são correlacionadas e os ele 
mentos da diagonal $\lambda_{1}, \ldots, \lambda_{v}$ podem ser determinados como as raizes da equação $|S-\lambda I|=0$, onde $I$ é matriz diagonal ( $\mathrm{v} \times \mathrm{v}$ ) com todos os elementos iguais a um. Os valores de $\lambda$ satisfazem três pro priedades:

1) $\lambda_{1} \geq \lambda_{2} \geq \cdots \geq \lambda_{\mathrm{v}}$;

2) $\sum_{i=1}^{v} \lambda_{i}=\sum_{i=1}^{v} s_{i}^{2}=$ traço de $s$, onde $s_{i}^{2} \vec{e}$ a variância da i-és $\underline{i}$ ma cultivar; e

3) $\prod_{i=1}^{v} \lambda_{i}=|s|$.

Uma vez os autovalores tenham sido calculados, os elementos de $A=\left[a_{1}, a_{2}, \ldots, a_{v}\right]$, onde o autovetor $a_{i} \bar{e}$ um vetor coluna de $\underline{\mathrm{v}}$ componentes, $i=1, \ldots, \mathrm{v}$, podem ser gerados como soluções das equações

$$
\left(s-\lambda_{i} \text { I }\right) a_{i}=0,(i=1, \ldots, v)(3 \cdot 2 \cdot 2 \cdot 2 . b)
$$

com a restrição de que $a_{i}^{\prime} a_{i}=1$.

$$
\text { Pós-multiplicando a matriz ( }(x \mathrm{v}) \text { dos efeitos da in }
$$
teração cultivar x local por A, tem-se o conjunto dos componentes principais. 0 i-ésimo componente tem uma variância igual a $\lambda_{i}$ e cor responde a uma proporção $\omega_{i}$ da variabilidade total presente na matriz $\mathrm{S}$, onde $\mathrm{W}_{i}=\lambda_{i} / \sum_{i=1} \lambda_{i}$. Se $\mathrm{W}_{1}$ apresentar uma variabilidade apreciāvel $\left(W_{1} \geq 0,80\right)$, os locais podem ser ordenados com base no primeiro componente. Se $\mathrm{W}_{1}+\mathrm{W}_{2}$ for igual ou maior que 0,80 , os 
dois primeiros componentes podem ser representados por dois eixos de coordenadas e seus elementos podem ser usados como coordenadas ao colocar no gráfico os pontos para os diferentes locais, identifican do possíveis conglomerados.

\subsubsection{3 - Anālise de variâveis canônicas}

Um terceiro método adaptado ao problema é o método de anālise de variáveis canônicas. Cada local è representado por um ponto em um espaço de $\underline{t}$ dimensões, definido por

$$
I_{k}=\left[(C L)_{1 k},(C L)_{2 k}, \ldots,(C L)_{t k}\right],(3.2 .2 .3 . a)
$$

onde $t$ é o número de cultivares comuns aos anos em estudo.

o objetivo de uma anālise de variāveis canônicas $\bar{e}$, à semelhança da anālise de componentes principais, condensar nos pri meiros eixos a maior parte da variabilidade existente nas $\underline{t}$ dimensões, eixos esses definidos pelos autovetores, tal que a configuração espacial dos pontos possa ser realmente representada.

$$
\text { Se, no modelo geral (3.2.1.a), Y }{ }_{i m k} \text { é a resposta mé- }
$$

dia (sobre repetições) da i-ésima cultivar no m-ésimo ano eno k-ésí mo local, então $\bar{Y}_{\text {.mk }} \bar{e}$ a média (sobre cultivares) para cada um dos $\underline{\text { n }}$ ambientes, e a expressão seguinte será verdadeira:

$$
\mathrm{Y}_{\mathrm{imk}}-\overline{\mathrm{Y}}_{. \mathrm{mk}}=\widehat{C}_{\mathrm{i}}+(\hat{\mathrm{CL}})_{i k}+(\mathrm{CA})_{i m}+(\widehat{\mathrm{CAL}})_{\mathrm{imk}},(3 \cdot 2 \cdot 2 \cdot 3 \cdot \mathrm{b})
$$

onde $\widehat{C}_{i}$ é o efeito estimado da i-ésima cultivar e os componentes res 
tantes são estimativas dos efeitos das interações de primeira e segunda ordem com locais e anos.

A transformação dos dados como em (3.2.2.3.b) permite a construção de duas matrizes de variâncias e covariâncias, de di mensões $t \times t$, denominadas: uma matriz $\mathrm{H}$ para a interação cultivar $x$ local, e uma matriz $E$ para a interação cultivar $x$ local $x$ ano. Os autovetores $p_{i}(i=1, \ldots, t)$ são, então, gerados como soluções das equações (SEAL, 1964)*

$$
\left(\mathrm{HE}^{-1}-\phi_{i} \text { I) } \mathrm{p}_{i}=0,\right.
$$

onde $\phi_{i}$ é o i-ésimo autovalor da matriz $\mathrm{HE}^{-1}$. Esses autovalores são extraỉdos em uma ordem decrescente de magnitude. Os autovetores cor respondentes são então usados na maneira usual para transformar as coordenadas (3.2.2.3.a) de cada local em novas coordenadas, conheci das como variāveis canônicas.

Uma vez que a primeira variável canônica representa um eixo inclinado na direção da maior variabilidade entre locais e a segunda é um eixo perpendicular ao primeiro e representa a próxima maior variabilidade, e assim sucessivamente, somente as primeiras variāveis canônicas serão de importância prática, e o método po de constituir-se num critério de classificação.

Análises de variância das primeiras variāveis canônicas são realizadas e o efeito de locais é testado, com o objetivo de identificar possíveis agrupamentos. As anālises de variância se(*) Vide descrição teórica do método no Apêndice. 
guem o esquema de anālise univariada, em delineamento inteiramente casualizado, apresentado na Tabela 3.

Tabela 3 - Esquema de anālise de variância das primeiras variáveis canônicas.

\begin{tabular}{lc}
\hline Fontes de Variação & G.L. \\
\hline Locais & $\ell-1$ \\
Resỉduo & $\ell(a-1)$ \\
\hline Total & $\ell a-1$ \\
\hline
\end{tabular}

\subsection{3 - Anālise de estabil idade}

Adota-se como procedimento de anālise de estabilidade uma adaptação do método de EBERHART e RUSSEL (1966). Estuda-se o modelo de regressão

$$
Y_{i j q}=\mu_{i}+\beta_{i} I_{j q}+\delta_{i j q}
$$

onde $\mathrm{Y}_{i j q}$ é a resposta da i-êsima cultivar na j-ésima repetição e no $q$-és imo ambiente $(i=1, \ldots, t ; j=1, \ldots, r ; q=1, \ldots, n), \mu_{i}$ é a média da i-ésima cultivar sobre todos os ambientes, $\beta_{i}$ é o coeficiente de re gressão que mede a resposta da i-ésima cultivar nos vārios ambientes, $\delta_{i j q}$ é o desvio da regressão da i-ésima cultivar na j-ésima re petição e no q-ésimo ambiente, e $I_{j q} \bar{e}$ o indice de ambiente obtido como a média de todas as cultivares na j-ésima repetição e no q-és 
mo ambiente menos a média geral:

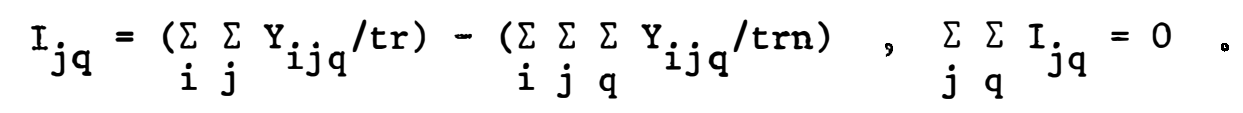

Com o modelo (3.2.3.a), as somas de quadrados devidas a ambiente e cultivar $x$ ambiente são repartidas em ambiente (1 $\underline{i}$ near), cultivar $x$ ambiente (linear) e desvios do modelo de regressão.

$$
\text { Os desvios }\left[\hat{\delta}_{i j q}=\left(Y_{i j q}-\hat{Y}_{i j q}\right)\right] \text { podem ser elevados }
$$

ao quadrado e somados para proporcionar uma estimativa de um parâme tro de estabilidade, dada por $\mathrm{s}_{\mathrm{di}}^{2}$, onde

$$
\mathrm{s}_{\mathrm{di}}^{2}=\sum_{j \mathrm{q}} \sum_{\mathrm{ijq}} \hat{\delta}_{\mathrm{i}}^{2} /(\mathrm{n}-2)-\mathrm{s}_{\mathrm{e}}^{2}, \quad, \quad(3 \cdot 2 \cdot 3 \cdot \mathrm{b})
$$

onde $s_{e}^{2}$ é a estimativa do erro, e

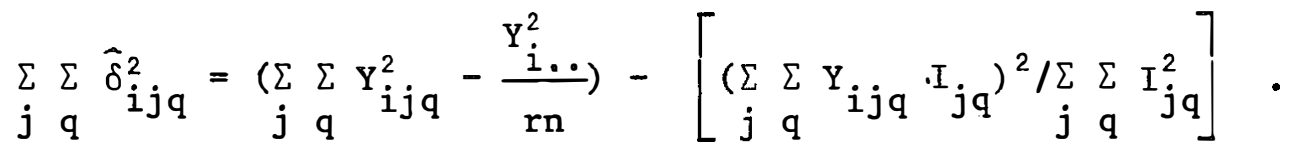

Este modelo permite fazer a partição da interação cu1 tivar $\mathrm{x}$ ambiente de cada cultivar em duas partes:

(1) a variação devida à resposta da cultivar sobre os vārios in dices de ambiente (somas de quadrados devidas à regressão);

(2) os desvios da regressão sobre o indice de ambiente. 


\begin{abstract}
A definição de uma cultivar estável, neste estudo, serā aquela com média alta e o desvio da regressão (parte não 1inear) tão pequeno quanto possĩvel。

Un teste do desvio da regressão para cada cultivar

é obtido por
\end{abstract}

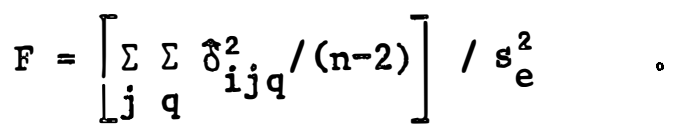


37 .

\title{
4. RESULTADOS E DISCUSSÃO
}

\begin{abstract}
As anālises realizadas neste trabalho foram efetuadas no Computador IBM 370, modelo 145, da Empresa Brasileira de Pes quisa Agropecuāria (EMBRAPA)。
\end{abstract}

\section{1 - Estimativas de Componentes de Variāncia}

As anālises individuais possibilitam calcular o coeficiente de variação (C.V.) de cada experimento, sendo $10 \%$ e $23 \%$ o menor e o maior $\mathrm{C} . \mathrm{V}$. encontrados, respectivamente. Cumpre observar que os experimentos com C.V. maior que $25 \%$ foram previamente exclui dos do presente trabalho.

Os componentes de variância estimados pressupõem que a variância do erro è homogênea dentro dos conjuntos de ambientes em estudo e a heterogeneidade de variância encontrada perturba os tes- 
tes de significância. Em vista disso, um teste $\mathrm{F}$ mais conservador é aplicado (COCHRAN e COX, 1957), o qual compara o F calculado da maneira usual com aquele tabulado com v-1 graus de liberdade para o numerador, onde $\underline{v} \bar{e}$ o número de cultivares testados, e n' graus de liberdade para o denominador, onde $n^{\prime} \bar{e}$ o número de graus de 1 iberdade do erro no experimento com maior quadrado médio residual, dentre aqueles experimentos usados na análise.

As estimativas dos componentes de variância, obtidas a partir das anālises de variância conjuntaspara cada uma das regiões II, III e IV, nos três anos, são apresentadas na Tabela 4 .

Observa-se que as estimativas dos componentes de variância correspondentes a cultivar, local e interação cultivar $x$ 1o cal $\left(\theta_{C}^{2}, \sigma_{L}^{2}\right.$ e $\left.\sigma_{C L}^{2}\right)$ são significativas para todas as combinações de região e ano, com exceção do componente $\sigma_{L}^{2}$ para as regiões II e III no ano de 1975, e o componente $\theta_{C}^{2}$ para a região IV nos anos de 1976 e 1977 .

A variância de uma média de cultivar em um certo ano é dada por $\left(\frac{\sigma_{\mathrm{e}}^{2}}{\mathrm{r} \ell}+\frac{\sigma_{\mathrm{CL}}^{2}}{\ell}\right)$, onde $\underline{\mathrm{r}} \overline{\mathrm{e}}$ o nümero de repetições por local e $\underline{\ell}$ é o número de locais de teste. A proporção dessa variância, devida a $\sigma_{\mathrm{CL}}^{2} / \ell$ pode ser expressa como $\mathrm{P}=\frac{\mathrm{rh}}{1+\frac{\mathrm{rh}}{1}}$, onde $\mathrm{h}=\frac{\sigma_{\mathrm{CL}}^{2}}{\sigma_{\mathrm{e}}^{2}}$. As est $\underline{\mathrm{i}}$ mativas de $\mathrm{P}$ para a região II são $0,38,0,48$ e 0,65 ; para a região III, 0,49, 0,57 e 0,68 e para a região IV, $0,62,0,78$ e 0,77 , respectivamente para os anos de 1975, 1976 e 1977. Esses resultados in 
dicam que a variância de uma média de cultivar, quando estimada den tro de um único ano, é composta em razoável proporção da interação cultivar x local. Contudo, deve-se notar que $\sigma_{\mathrm{CL}}^{2}$ estimado a partir de dados de um único ano é apenas uma parte da variância cultivar $x$ $x$ ambiente representada por $\sigma_{C L}^{2}+\sigma_{C A}^{2}+\sigma_{C L A}^{2}$, quando se considera a anālise de variância conjunta sobre anos.

Tabela 4 - Estimativas de $\theta_{C}^{2}, \sigma_{L}^{2}, \sigma_{C L}^{2}$ e $\sigma_{e}^{2}$, para as regiões II, III e IV, nos anos de 1975, 1976 e 1977.

\begin{tabular}{|c|c|c|c|c|}
\hline \multirow{2}{*}{ ANO } & \multirow{2}{*}{$\begin{array}{l}\text { COMPONENTE } \\
\text { ESTIMADO }\end{array}$} & \multicolumn{3}{|c|}{ R E G I $\tilde{A} O$} \\
\hline & & II & III & IV \\
\hline \multirow{4}{*}{1975} & $\theta_{\mathrm{C}}^{2}$ & $25.071 *$ & $27.838 * *$ & $14.367 * *$ \\
\hline & $\sigma_{\mathrm{L}}^{2}$ & $776 \mathrm{~ns}$ & $30 \mathrm{~ns}$ & $300.350 * *$ \\
\hline & $\sigma_{\mathrm{CL}}^{2}$ & $18.089 *$ & $9.648 *$ & $10.620 * *$ \\
\hline & $\sigma_{\mathrm{e}}^{2^{L}}$ & 88.620 & 30.483 & 19.576 \\
\hline \multirow{4}{*}{1976} & $\theta_{\mathrm{C}}^{2}$ & $78.188 * *$ & $39.669 * *$ & $22.932 \mathrm{~ns}$ \\
\hline & $\sigma_{\mathrm{L}}^{2}$ & $77.884 * *$ & $70.589 * *$ & $225.642 * *$ \\
\hline & $\sigma_{\mathrm{CL}}^{2}$ & $20.327 *$ & $26.239 * *$ & $42.190 * *$ \\
\hline & $\sigma_{e}^{2}$ & 64.850 & 58.958 & 36.263 \\
\hline \multirow{4}{*}{1977} & $\theta_{\mathrm{C}}^{2}$ & $79.522 * *$ & $49.814 * *$ & $12.830 \mathrm{~ns}$ \\
\hline & $\sigma_{L}^{2}$ & $3.789 * *$ & $2.035 * *$ & $324.701 * *$ \\
\hline & $\sigma_{\mathrm{CL}}^{2}$ & $11.939 * *$ & $9.693 * *$ & $25.165 * *$ \\
\hline & $\sigma_{\mathrm{e}}^{2}$ & 18.986 & 13.872 & 23.124 \\
\hline
\end{tabular}

ns = não significativo;

* = significativo ao nivel de $5 \%$ de probabilidade; ** = significativo ao nivel de $1 \%$ de probabilidade. 
As estimativas dos componentes de variância obtidas a partir das anālises de variância conjuntas das regiões II, III e IV, dentro de cada ano, são apresentadas na Tabela 5. Essas estimativas possibilitam o estudo da magnitude relativa dos componentes de variância de cultivar e da interação cultivar $x$ região e cultivar $x$ x local dentro de região, na atual regionalização.

Tabela 5 - Estimativas de $\theta_{C}^{2}, \theta_{C R}^{2}, \sigma_{C L(R)}^{2}$ e $\sigma_{e}^{2}$ das anālises conjuntas das regiões II, III e IV, dentro de cada ano.

\begin{tabular}{ccc}
\hline ANO & $\begin{array}{c}\text { COMPONENTE } \\
\text { ESTIMADO }\end{array}$ & ESTIMATIVA \\
\hline & $\theta_{\mathrm{C}}^{2}$ & $18.930 * *$ \\
& $\theta_{\mathrm{CR}}^{2}$ & $6.934 *$ \\
& $\sigma_{\mathrm{CL}(\mathrm{R})}^{2}$ & $10.665 *$ \\
& $\sigma_{\mathrm{e}}^{2}$ & 40.927 \\
& & \\
& $\theta_{\mathrm{C}}^{2}$ & $35.078 * *$ \\
& $\theta_{\mathrm{CR}}^{2}$ & $15.387 * *$ \\
& $\sigma_{\mathrm{CL}(\mathrm{R})}^{2}$ & $28.527 * *$ \\
& $\sigma_{\mathrm{e}}^{2}$ & 54.757 \\
& & $43.743 * *$ \\
& $\theta_{\mathrm{C}}^{2}$ & $4.175 \mathrm{~ns}$ \\
& $\theta_{\mathrm{CR}}^{2}$ & $13.9 .52 * *$ \\
& $\sigma_{\mathrm{CL}(\mathrm{R})}^{2}$ & 17.976 \\
& $\sigma_{\mathrm{e}}^{2}$ &
\end{tabular}

ns = não significativo;

* = significativo ao nivel de $5 \%$ de probabilidade; ** = significativo ao nível de $1 \%$ de probabilidade. 
As estimativas de componentes de variância correspon dentes à interação cultivar x região, apreciavelmente maior que zero nos anos de 1975 e 1976, indicam alguma vantagem na separação dos locais nas três regiões, para este particular conjunto de cultivares, nos dois anos considerados. A correlação intra classe $\frac{\theta_{C R}^{2}}{\theta_{C R}^{2}+\sigma_{C L(R)}^{2}}$ compara a magnitude dos dois componentes acima referenciados e assu me os valores de 0,39, 0,35 e 0,23 nos anos de 1975, 1976 e 1977 , respectivamente. A média para os três anos $(0,32)$ indica que a atual regionalização estā contribuindo, em mëdia, para a diminuição de $32 \%$ do total da interação cultivar x local.

As estimativas dos componentes de variância, obtidos a partir das anālises de variância conjuntas de todos os locais, em cada ano, ignorando região, são apresentadas na Tabela 6.

Estas estimativas indicam que a atual regionalização tem alguma eficiência quando se compara em cada ano as estimativas dos componentes de variância da interação cultivar x local com o correspondente componente de variância dentro dé região da análise anteriormente referenciada (Tabela 5). As estimativas de $\mathrm{P}$ são 0,54, 0,69 e 0,74, respectivamente, para os anos de 1975, 1976 e 1977. 
Tabela 6 - Estimativas de $\theta_{C}^{2}, \sigma_{L}^{2}, \sigma_{C L}^{2}$ e $\sigma_{e}^{2}$ das anālises conjuntas de todos os locais das regiões II, III e IV, dentro de cada ano.

\begin{tabular}{ccc}
\hline ANO & $\begin{array}{c}\text { COMPONENTE } \\
\text { EST IMADO }\end{array}$ & ESTIMATIVA \\
\hline & $\theta_{\mathrm{C}}^{2}$ & $18.269 * *$ \\
& $\sigma_{\mathrm{L}}^{2}$ & $303.199 * *$ \\
& $\sigma_{\mathrm{CL}}^{2}$ & $15.948 * *$ \\
& $\sigma_{\mathrm{e}}^{2}$ & 40.927 \\
& $\theta_{\mathrm{C}}^{2}$ & \\
& $\sigma_{\mathrm{L}}^{2}$ & $33.614 * *$ \\
& $\sigma_{\mathrm{CL}}^{2}$ & $96.527 * *$ \\
& $\sigma_{\mathrm{e}}^{2}$ & $40.240 * *$ \\
& & 54.757 \\
& $\theta_{\mathrm{C}}^{2}$ & \\
& $\sigma_{\mathrm{L}}^{2}$ & $43.279 * *$ \\
& $\sigma_{\mathrm{CL}}^{2}$ & $58.632 * *$ \\
& $\sigma_{\mathrm{e}}^{2}$ & $17.199 * *$ \\
& & 17.976 \\
\hline
\end{tabular}

$* *$ = significativo ao nível de $1 \%$ de probabilidade.

As estimativas dos componentes de variância, obtidas a partir da análise de variância conjunta de locais e anos, ignoran do regiões, são apresentadas na Tabela 7 . 
Tabela 7 - Estimativas de $\theta_{C}^{2}, \sigma_{C L}^{2}, \sigma_{C A}^{2}, \sigma_{C L A}^{2}$ e $\sigma_{e}^{2}$ das anälises conjuntas de locais e anos, ignorando regiões.

\begin{tabular}{cc}
\hline $\begin{array}{c}\text { COMPONENTE } \\
\text { ESTIMADO }\end{array}$ & ESTIMATIVA \\
\hline$\theta_{\mathrm{C}}^{2}$ & $50.442 * *$ \\
$\sigma_{\mathrm{CL}}^{2}$ & $605 \mathrm{~ns}$ \\
$\sigma_{\mathrm{CA}}^{2}$ & $22.569 * *$ \\
$\sigma_{\mathrm{CLA}}^{2}$ & $20.098 * *$ \\
$\sigma_{\mathrm{e}}^{2}$ & 42.989 \\
\hline
\end{tabular}

ns = não significativo;

** = significativo ao nível de $1 \%$ de probabilidade.

A estimativa do componente de variância da interação cultivar $x$ local não difere significativamente de zero. Os componen tes das interações cultivar $\mathrm{x}$ ano e cultivar $\mathrm{x}$ local $\mathrm{x}$ ano são significativos ao nivel de $1 \%$ de probabilidade. Essses resultados sugerem que as cultivares utilizadas nesta anālise (IAS 54, Jacuí, Maringá, PAT 24 e.PF 7158) apresentam desempenho semelhante nos diferentes locais na média dos anos, mas diferem atravēs dos anos na mé dia dos locais. A presença significativa do componente da interação de segunda ordem indica que a interação cultivar x local difere nos diversos anos, ou seja, as cultivares respondem diferentemente quando expostas a diferentes ambientes. 
Em testes repetidos sobre anos e locais, a proporção da variância de uma média de cultivar atribuível a $\sigma_{C L}^{2}$ pode ser expressa como

$$
P^{\prime}=\frac{r a h_{1}}{1+r a h_{1}+r h_{2}+r l h_{3}}
$$

onde $\underline{r}$ é o número de repetições, a $\circ$ número de anos e $\underline{\ell}$ o número de locais; e

$$
h_{1}=\frac{\sigma_{C L}^{2}}{\sigma_{e}^{2}}, \quad h_{2}=\frac{\sigma_{C L A}^{2}}{\sigma_{e}^{2}}, \quad h_{3}=\frac{\sigma_{C A}^{2}}{\sigma_{e}^{2}} .
$$

A estimativa de $P^{\prime} \bar{e} 0,01$, e as grandes diferenças en tre $P$ e $P^{\prime}$ refletem a elevada tendenciosidade devida a $\sigma_{\text {CLA }}^{2}$ na esti mativa de $\sigma_{\mathrm{CL}}^{2}$ das anālises conjuntas de todos os locais das regiões II, III e IV, dentro de cada ano.

Os resultados obtidos com os componentes de variância, no estudo da natureza das interações cultivar $\mathrm{x}$ ambiente, mostram que as estimativas de $\sigma_{C L}^{2}$, a partir de dados de um único ano, são bastante tendenciosas, devido à presença significativa das inte rações cultivar $x$ ano e cultivar x local x ano. Observa-se, também, que o número de locais de teste e o número de cultivares comuns nos três anos em estudo, bem como o número reduzido de anos, limitam, em parte, o valor das estimativas dos diversos componentes de variância, especialmente na anālise sobre os anos. Contudo, apesar do número reduzido de anos utilizados no estudo, eles se mostram bastante representativos, com produção média de $1.152 \mathrm{~kg} / \mathrm{ha}, 1.561 \mathrm{~kg} / \mathrm{ha} \mathrm{e}$ $833 \mathrm{~kg} / \mathrm{ha}$, para os anos de 1975, 1976 e 1977, respectivamente. 
0 estudo da natureza das interações cultivar $\mathrm{x}$ ambiente indica alguma vantagem na separação dos locais nas três regiões da atual regionalização do Estado. Isto se verifica nas anāli ses regionais realizadas dentro de cada ano em estudo.

\section{2 - Classificação dos Locais}

\subsection{1 - Anālise de conglomeração}

As relações entre os locais, resultantes da aplicação do método de anālise de conglomeração, utilizando todas as cultivares ensaiadas, aplicado sobre todos os locais das regiões II, III e IV, em cada um dos anos em estudo, são representadas por meio de dendogramas. As Figuras 2, 3 e 4 apresentam os dendogramas relativos a cada ano analisado. Os locais são identificados pela numera ção indicada na Tabela 2.

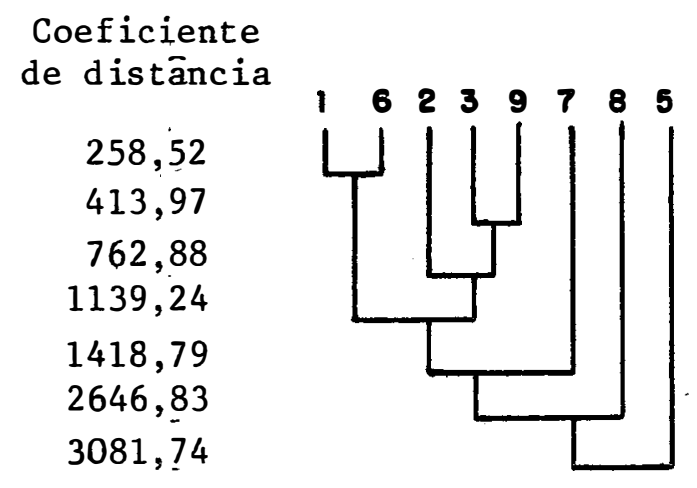

Figura 2 - Ano de 1975 (31 cultivares). 


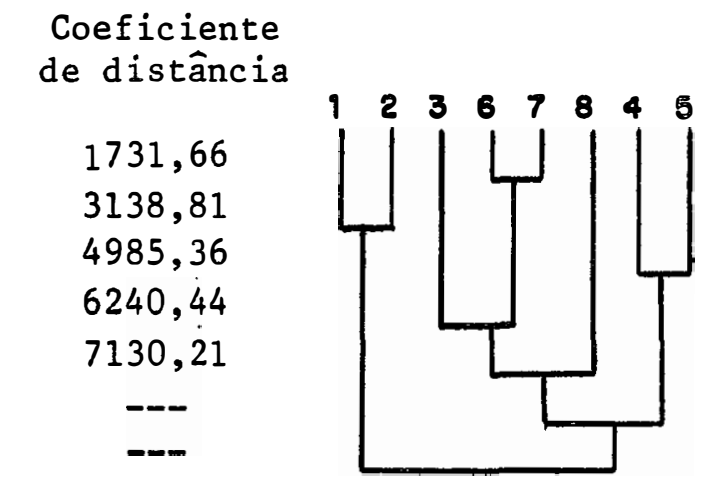

Figura 3 - Ano de 1976 (28 cultivares)

$$
\begin{gathered}
\text { Coeficiente } \\
\text { de distância } \\
117,98 \\
282,22 \\
463,41 \\
1094.78 \\
1941,35 \\
3751,91
\end{gathered}
$$

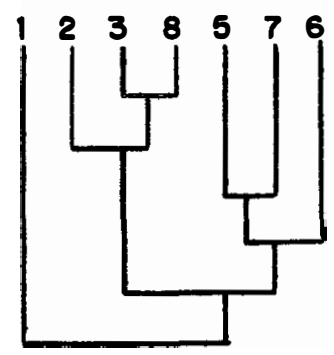

Figura 4 - Ano de 1977 (20 cultivares)

Observando os dendogramas das Figuras 2, 3 e 4, ver $\underline{i}$ fica-se pouca consistência na classificação dos locais entre os anos analisados.

As relações entre os locais, considerando apenas as cinco cultivares comuns aos três anos em estudo, são apresentadas nos dendogramas das Figuras 5, 6 e 7 . 

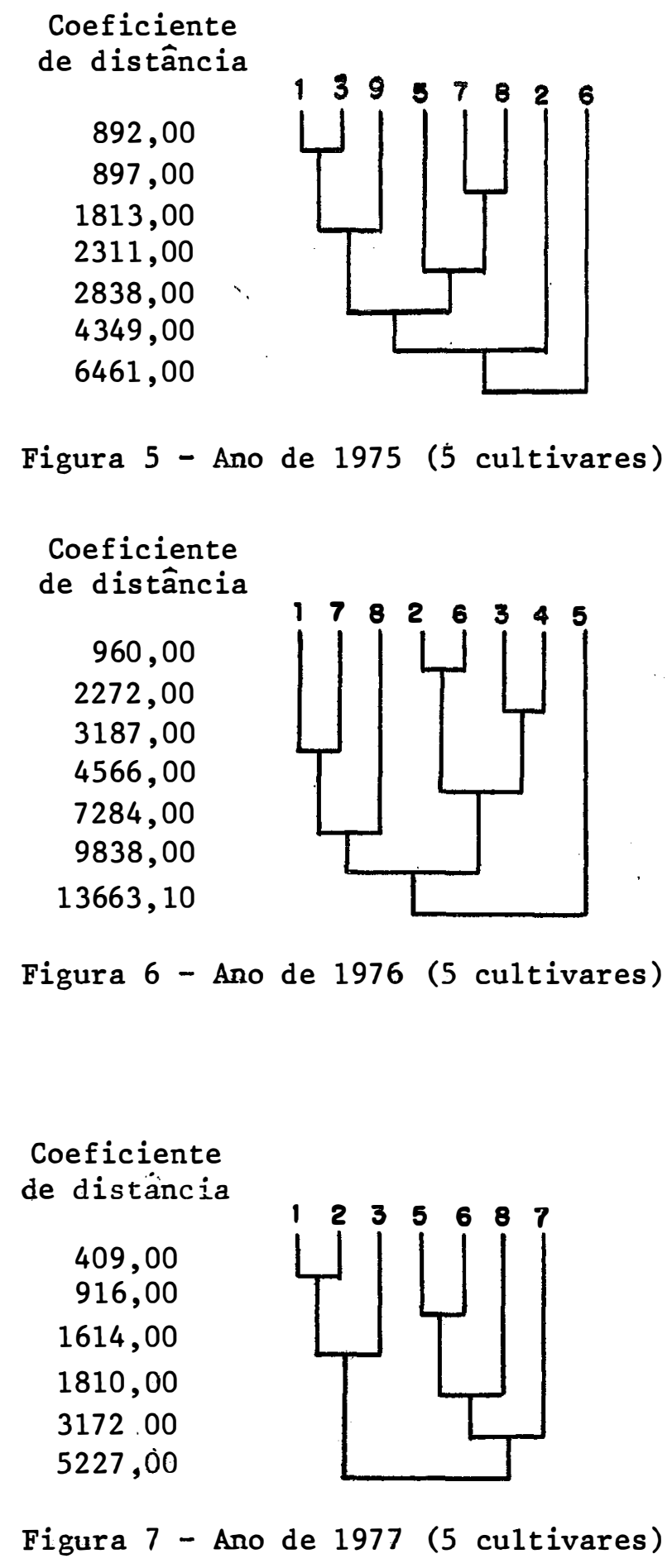
48.

Verifica-se, observando os dendogramas das Figuras 5, 6 e 7, que permanece a pouca consistência na classificação dos locais entre os anos estudados. Isto é decorrência da presença significativa da interação cultivar $x$ local $x$ ano, apresentada na Tabe1 a 7 .

\subsection{2 - Anālise de componentes principais \\ 0 resultado da anālise de componentes principais,con} siderando todas as cultivares ensaiadas, dentro de cada ano em estu do, é apresentado na Tabela 8 .

Verifica-se, pela Tabela 8, que a variabilidade apre senta-se bastante diluỉda nos primeiros eixos, não se podendo ordenar os locais através de coordenadas em um grä́fico, com o objetivo de identificar possiveis conglomerados.

0 resultado da análise de componentes principais,con siderando apenas as 5 cultivares comuns, dentro de cada ano em estu do, é apresentado na Tabela 9.

Pós-multiplicando a matriz ( $l \times \mathrm{v})$ dos efeitos da in teração cultivar x local pelos vetores $a_{1}$ e $a_{2}$ (Tabela 9.), obtêm-se as coordenadas para os diferentes locais. As Figuras 8, 9 e 10 apresentam graficamente os pontos para os diferentes locais, os quais são identificados pela numeração indicada na Tabela 2. 
49.

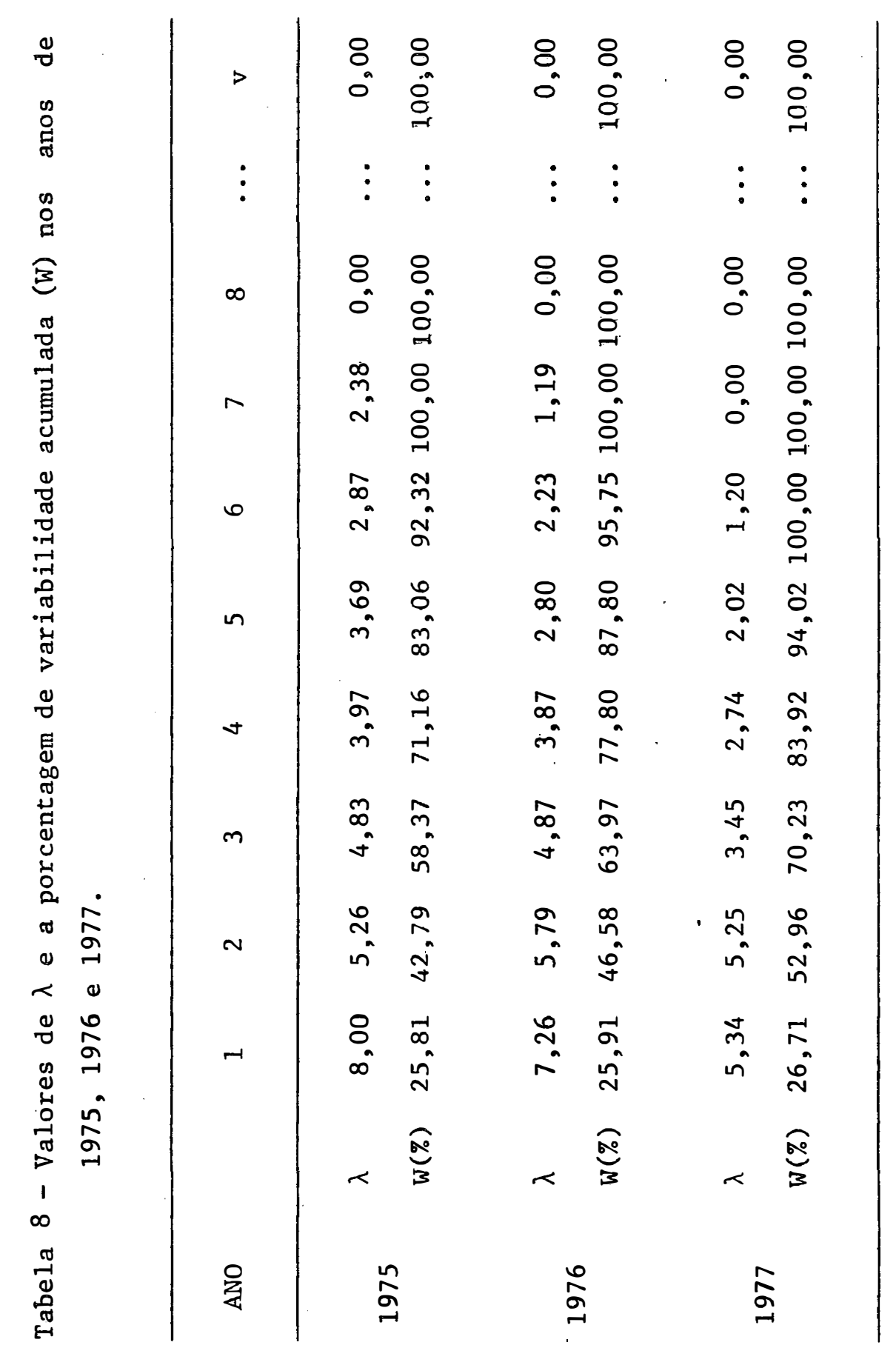




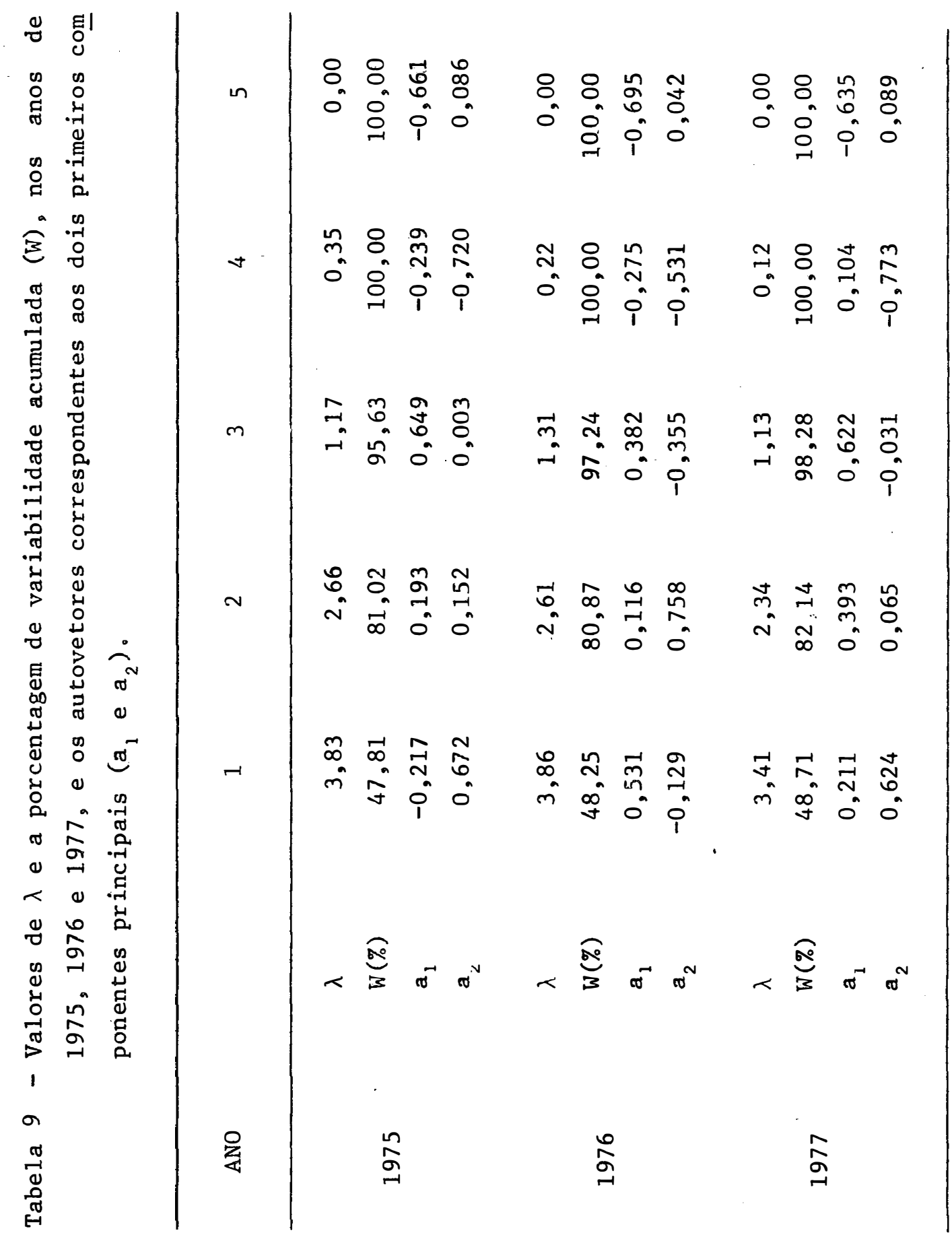


51.

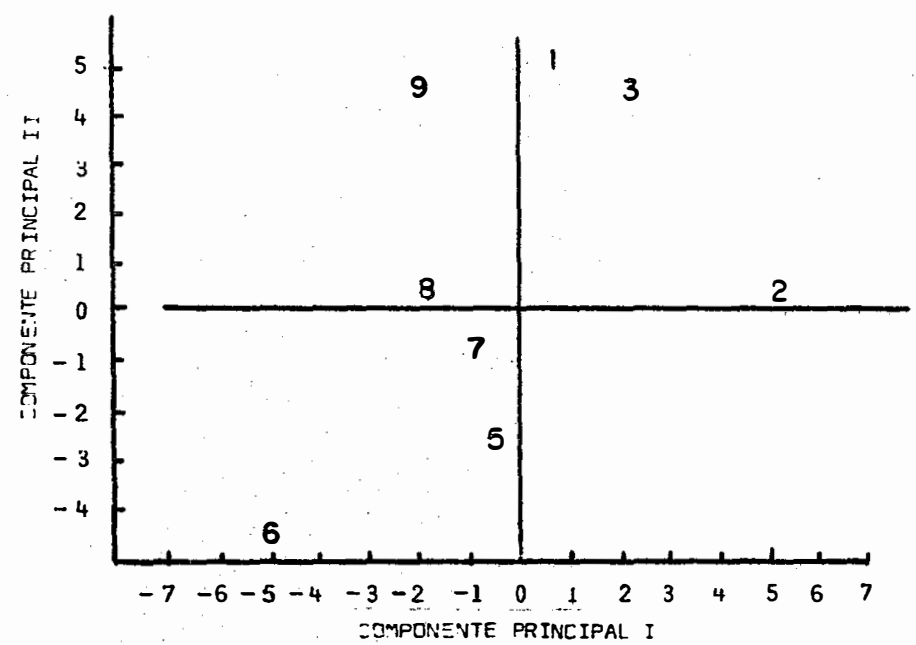

Figura 8 - Distribuição dos oito locais nos dois primeiros componentes principais (1975).

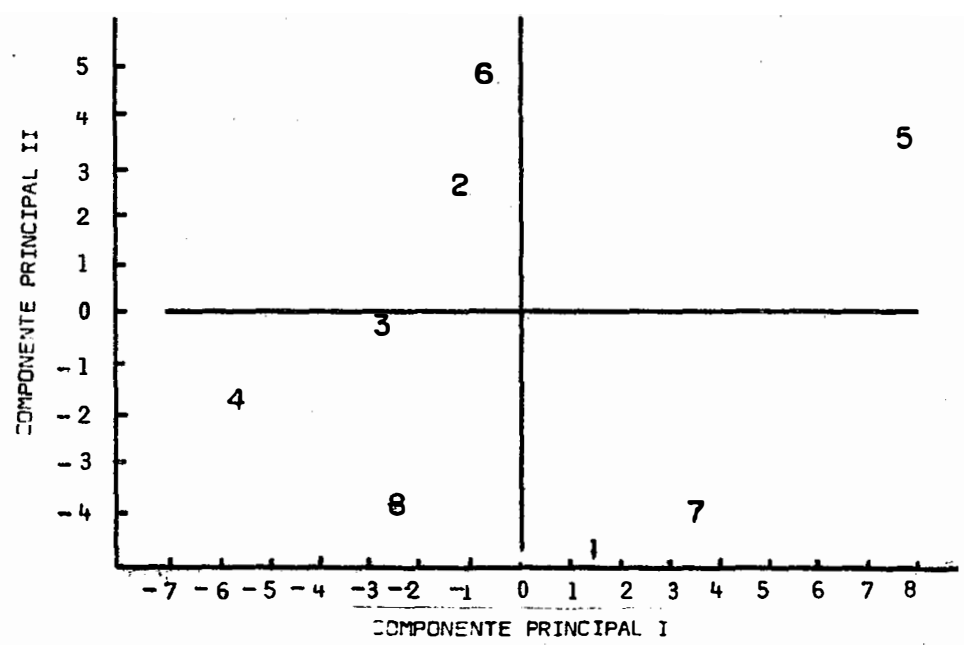

Figura 9 - Distribuição dos oito locais nos dois primeiros componentes principais (1976). 


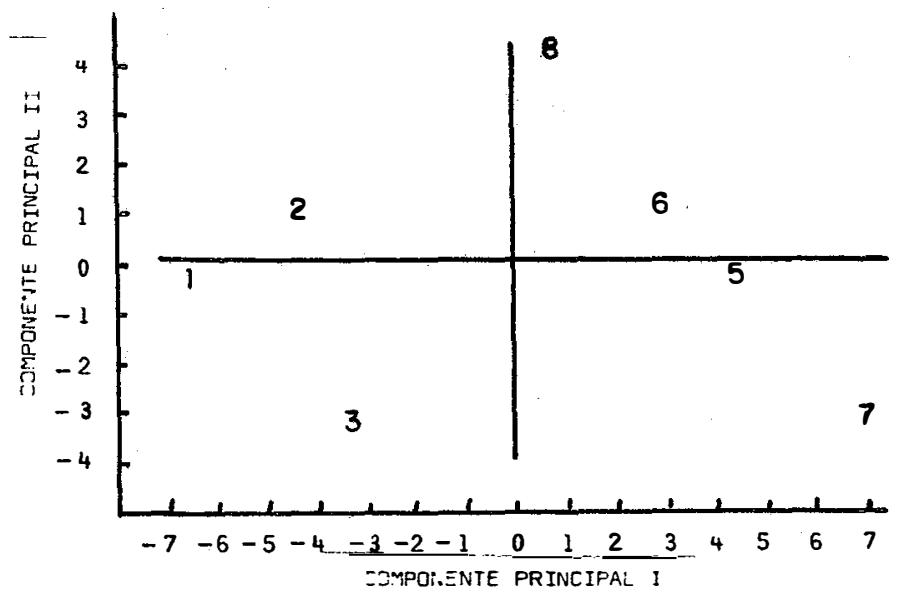

Figura 10 - Distribuiçăo dos sete locais nos dois primeiros componentes principais (i977).

Comparando-se as Figuras 5 e 8,6 e 9, 7 e 10, constata-se uma boa concordância entre os métodos de anālise de conglomeração e de anālise de componentes principais, sendo que alguma dis cordância é devida à supressão do 39 e 49 componentes principais.

\subsection{3 - Anālise de variāveis canōnicas}

As matrizes $H$ (entre) e $E$ (dentro) podem ser apresen tadas em um quadro de análise de variância multivariada (Tabela 10). 
Tabela 10 - Análise de variância multivariada, matrizes H e E.

\begin{tabular}{|c|c|c|c|c|c|c|}
\hline & \multirow{2}{*}{ G.I. } & \multicolumn{5}{|c|}{ CULTIVAR } \\
\hline & & 1 & 2 & 3 & 4 & 5 \\
\hline \multirow{5}{*}{ Matriz H } & \multirow{5}{*}{8} & 158.589 & -99.452 & 27.382 & -48.163 & -38.491 \\
\hline & & -99.452 & 274.915 & -66.363 & -52.343 & -56.767 \\
\hline & & 27.382 & -66.363 & 254.948 & -73.779 & -142.212 \\
\hline & & -48.163 & -52.343 & -73.779 & 203.035 & -28.640 \\
\hline & & -38.491 & -56.767 & -142.212 & -28.640 & $266.171\rfloor$ \\
\hline \multirow{5}{*}{$\begin{array}{l}\text { Matriz E } \\
=14 \hat{\Sigma}_{\Omega}\end{array}$} & \multirow{5}{*}{14} & {$[378.591$} & 278.930 & -247.125 & -330.459 & $-80.030\rceil$ \\
\hline & & 278.930 & 8.27 .767 & -213.618 & -738.914 & -154.169 \\
\hline & & -247.125 & -213.618 & 705.878 & -37.034 & -208.079 \\
\hline & & -330.459 & -738.915 & -37.034 & 973.237 & 133.251 \\
\hline & & -80.030 & -154.169 & -208.079 & 133.251 & 309.026 \\
\hline \multirow{5}{*}{$\begin{array}{l}\text { Matriz } \\
\text { Total } \\
=22 \widehat{\Gamma}_{\mathrm{w}}\end{array}$} & \multirow{5}{*}{22} & {$[537.180$} & 179.478 & -219.743 & -378.622 & $-118.521]$ \\
\hline & & 179.478 & 1.102 .682 & -279.981 & -791.257 & -210.936 \\
\hline & & -219.743 & -279.981 & 960.826 & -110.813 & -350.291 \\
\hline & & -378.622 & -791.258 & -110.813 & 1.176 .272 & 104.611 \\
\hline & & -118.521 & -210.936 & -350.291 & 104.611 & 575.197] \\
\hline
\end{tabular}

Da variação entre locais, $82 \%$ estā representada pelos dois primeiros autovalores. Um exame dos elementos de seus auto vetores correspondentes (Tabela 11) revela que a maior parte da variabilidade no primeiro autovetor é devida ao contraste nos diferen tes locais da cultivar IAS 54 contra Jacuí, Maringá, PAT 24 e PF 
54.

7158. O segundo autovetor não revela nenhum contraste apreciável en tre cultivares.

Tabela 11 - Primeiros dois autovetores gerados pela análise de variāveis canônicas.

\begin{tabular}{ccc}
\hline CULTIVAR & VETOR I $\left(\mathrm{p}_{1}\right)$ & VETOR I $\left(\mathrm{p}_{2}\right)$ \\
\hline IAS 54 & 0,3041 & 1,3380 \\
Jacuỉ & $-0,3013$ & 1,3383 \\
Maringa & $-0,3031$ & 1,3382 \\
PAT 24 & $-0,3019$ & 1,3379 \\
PF 7158 & $-0,3034$ & 1,3395 \\
\hline Autovalor $(\phi)$ & 3,5198 & 1,1859 \\
\hline Porcentagem da & $62 \%$ & $20 \%$ \\
\hline
\end{tabular}

Anālises de variância das primeiras variáveis canôni cas não revelam diferença significativa entre locais. Valores da va riável canônica para cada local são colocados em um gráfico no primeiro e segundo eixos canōnicos (Figura 11).

Dentre a amostra de 9 locais nas regiões II, III e IV, embora exista uma grande e significativa interação cultivar x lo cal, entre nenhum local ela foi consistente de ano para ano. Assim, embora essa interação estivesse presente em cada um dos anos estuda dos, ela foi grandemente absorvida pela interação cultivar $x$ local 
$\mathbf{x}$ ano, em uma análise combinada sobre todos os anos. Isto confirma - resultado da análise de variância conjunta de locais e anos, igno rando regiões (Tabela 7), e a pouca consistência da interação cult $\underline{i}$ var x local entre os anos estudados é confirmada na anảlise de conglomeração e anālise de componentes principais.

A similaridade da distribuição dos locais nos dois eixos canônicos, e o resultado das análises de variância das primei ras variāveis canônicas sugerem que os locais das atuais regiões II, III e IV constituem uma única região no Estado, para a cultura do tri go, levando-se em conta as 5 cultivares estudadas.

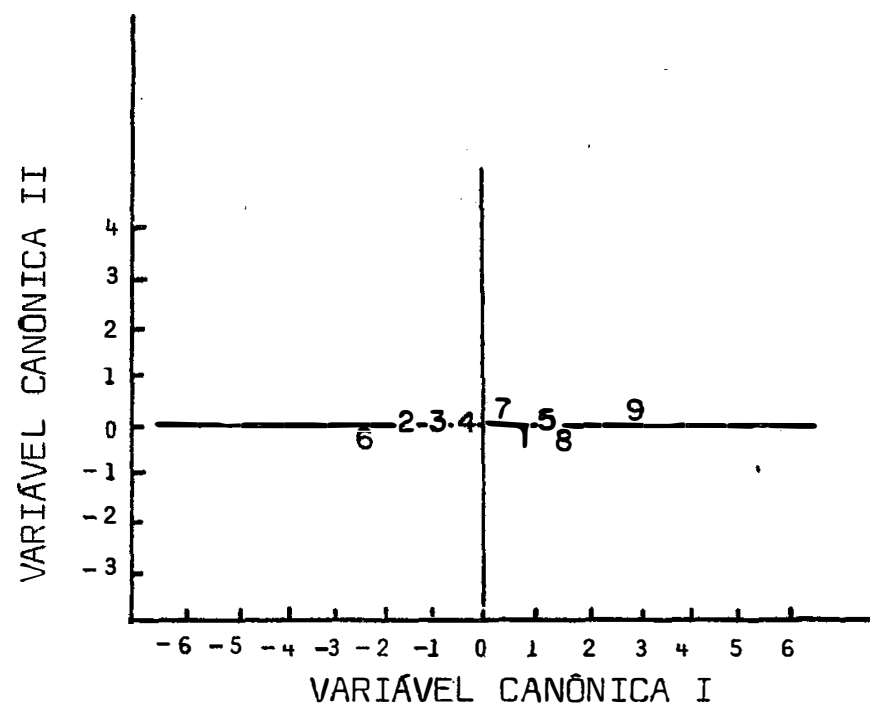

Figura 11 - Distribuição dos nove locais nas duas primeiras dimensões canônicas. 
56.

\section{3 - Anālise de Estabilidade}

A anālise de estabilidade è realizada inicialmente pa ra o conjunto dos 23 ambientes das regiões II, III e IV, e os resul tados são apresentados na Tabela 12 .

Tabela 12 - Parâmetro de estabilidade para as cinco cultivares, con siderando-se os 23 ambientes das regiões II, III e IV.

\begin{tabular}{|c|c|c|c|}
\hline CULTIVAR & $\begin{array}{c}\text { Rendimento médio } \\
\text { sobre todos os } \\
\text { ambientes } \\
(\mathrm{kg} / \mathrm{ha})\end{array}$ & $\begin{array}{l}\text { Percentagem } \\
\text { sobre a média } \\
\text { geral }\end{array}$ & $\begin{array}{l}\text { Desvio da } \\
\text { Regressão } \\
\quad\left(\mathrm{s}_{\mathrm{d}}^{2}\right)\end{array}$ \\
\hline IAS 54 & 863,7 & 71,5 & $9.403 \mathrm{~ns}$ \\
\hline Jacui & $1.333,0$ & 110,3 & $105.273 * *$ \\
\hline Maringā & $1.214,2$ & 100,5 & $84.885 * *$ \\
\hline PAT 24 & $1.140,8$ & 94,4 & $106.222 * *$ \\
\hline PF 7158 & $1.489,5$ & 123,3 & $37.076 *$ \\
\hline Média Geral & $1.208,3$ & & \\
\hline
\end{tabular}

Pela anālise da Tabela 12 , a cultivar IAS 54 atende aos requisitos de um cultivar estável. A cultivar PF 7158 apresenta um desvio da regressão levemente significativo e uma produtividade de $123,3 \%$ sobre a mëdia das cultivares nos 23 ambientes. 
Posteriormente è realizada anālise de estabilidade, para as mesmas cultivares, dentro de cada uma das regiões II ( 6 ambientes), III (10 ambientes) e IV (7 ambientes). Nas regiões II e III as cultivares IAS 54 e PF 7158 atendem aos requisitos de uma cu tivar estável, sendo a cultivar PF 7158 a preferida por ser a de maior média de produção entre as cultivares ensaiadas. Na região IV nenhuma cultivar apresenta os requisitos de estabilidade, embora a cultivar PF 7158 continuasse sendo a mais produtiva. 
58.

5. CONCLUSÕES

Com base nos resultados e discussão, podem ser tiradas, para as classificações ambientai.s baseadas na interação genōti po $\mathrm{x}$ ambiente com aplicação à cultura do trigo no Rio Grande do Sul, as seguintes conclusões:

5.1 - 0 estudo da natureza das interações cultivar $\mathbf{x}$ ambiente, através dos componentes de variância, indica alguma vantagem na separação dos locais nas três regiões da atual regionalização do Esta do. Isto se verifica nas anālises regionais realizadas dentro de cada ano em estudo.

5.2 - Este mesmo estudo mostra também que as estimativas de $\sigma_{C L}^{2}$, a partir de dados de um único ano, são tendenciosas, devido à presença significativa das interações cultivar $x$ ano e cultivar $x$ 10cal $x$ ano. 
5.3 - Em vista disto, os métodos de análise de conglomeração e de anālise de componentes principais, embora apresentem boa concordância entre si, não apresentam consistência na classificação dos locais entre os anos estudados.

5.4 - 0 método de análise de variáveis canônicas é aquele que me lhor se adapta ao caso em estudo, e os seus resultados indicam que os locais das atuais regiões II, III e IV se comportam como uma úni ca região no Estado, para as cinco cultivares consideradas.

5.5 - A análise de estabilidade mostra-se muito rigorosa, pois, revela para o conjunto dos ambientes, apenas uma das cinco cultivares atendendo aos requisitos de estabilidade.

0 método de análise de variáveis canônicas, em partí cular, possibilita as seguintes conclusões:

1) Primeiramente, ele leva em consideração a interação cultivar $x$ local x ano, a qual é confundida com cultivar x local (HORNER e FREY, 1957) ou ignorada (ABOU-EL-FITTOUH et alii, 1969), bem como leva em consideração a contribuição de cada local na interação cultivar x local. A classificação é, assim, consistente sobre os anos em estudo. Além disso, há menor chance de erro de classificação do que no método de conglomeração, porque tanto as distâncias entre 1o cais como suas direções são preservadas e representadas. A distribuição espacial dos locais é impossivel de representar em um diagra ma hierārquico tal como é usado na técnica de conglomeração aglome- 
60.

rativa.

2) Oferece um método prático de utilizar toda a informação em uma série de dados não balanceados, mesmo quando cada local não estả representado em cada ano.

3) Os resultados fornecem um meio de elucidar algumas das causas de variação devidas à interação cultivar x local. Os poucos prí meiros autovetores mostram as cultivares que causam a maior parte da interação e a forma de sua resposta aos ambientes dos diferentes locais. 
61.

\section{LITERATURA CITADA}

ABOU-EL-FITTOUH, H. e J.0. RAWLINGS, 1967. Genotype by Environment Interactions in Cotton - Their Nature Related Environmental Factors and Implications in Zoning. Raleigh, North Carolina State University, 132 pp. (Tese de Doutoramento).

ABOU-EL-FITTOUH, H.; J.O. RAWLINGS e P.A. MILLER, 1969. Classifica tions of Environments to Control Genotypes by Environment Interac tion with Application to Cotton. Crop Science. Madison, 9: 135-140 .

ALLARD, R.W. e A.D. BRADSHAW, 1964. Implications of Genotype Environment Interactions in Applied Plant Breeding. Crop Science. Madison, 4: 503-507. 
BARTLETT, M.S., 1938. Further Aspects of the Theory of Multiple Regression. Proceedings of the Cambridge Philosophical Society. Cambridge, 34: 33-40.

BREESE, E.L., 1969. The Measurement and Significance of Genotype-Environment Interactions in Grasses. Heredity. Londres, 24: $27-44$.

BYTH, D.E.: R.L. EISEMANN e H.I. DE LACY, 1976. Two-way Pattern Ana lysis of a Large Data Set to Evaluate Genotype Adaptation. Heredity. Londres, 37: 215-230.

CAMPBELL, L.G. e H.N. LAFEVER, 1977. Cultivar x Environment Interac tion in Soft Red Winter Yield Tests. Crop Science. Madison, 17: 607-608.

COCHRAN, W.G. e G.M. COX, 1957. Experimental Designs. 2a. ed., Nova York, John Wiley, 611 pp.

CORDEIRO, C.M.T., 1978. Estudo do Zoneamento da Região Centro-Sul do Brasil para a Cultura do Milho. Brasilia, Universidade de Brasilia, 104 pp. (Dissertação de Mestrado). .

EBERHART, S.A. e W.A. RUSSEL, 1966. Stability Parameters for Comparing Varieties. Crop Science. Madison, 6: 36-40.

FINLAY, K.W. e G.N. WILKINSON, 1963. The Analysis of Adaptation in Plant Breeding Programme. Australian Journal of Agricultural Research. Melbourne, 14: 742-754.

FREEMAN, G.H., 1973. Statistical Methods for the Analysis of Genotype-Environment Interactions. Heredity. Londres, 31: 339-354. 
63.

HORNER, T.W. e K.J. FREY, 1957. Methods for Determining Natural Areas for Oat Varietal Recommendations. Agronomy Journal. Wiscon sin, 49: 313-315.

JOWETT, D., 1972. Yield Stability Parameters for Sorghum in East Africa. Crop Science. Madison, 12: 314-317.

KEMPTHORNE, 0., 1975. The Design and Analysis of Experiments. Nova York, Robert E. Kreeger Publishing, 641 pp.

LIANG, G.H.L.; E.G. HEINE e T.L. WALTER, 1966. Estimates of Variety-Enviroment Interactions in Yield Test and Their Significance in Breeding Programs. Crop Science. Madison, 6: 135-139.

MAHALANOBIS, P.C., 1936. On the Generalized Distance in Statistics. Proceedings National Institute of Science. India, 12: 49-55.

MOREIRA, J.C.S.; E.A. OSÓRIO; M.C. MEDEIROS; F.A. LANGER; V.I. LINHARES; E.P. GOMES; C.N.A. SOUZA e G.C. COPPOLLA, 1971. Cultura do Trigo. Instituto de Pesquisas Agropecuārias do Sul. Pelotas, Circ. 48: 19-29.

MORRISON, D.F., 1976. Mu1tivariate Statistical Methods. $2^{a}$ ed. Nova York, McGraw-Hil1, 415 pp.

MOTA, F.S. e M.I.C. BEIRSDORF, 1971. Cultura do Trigo no Rio Grande do Sul e Santa Catarina. Instituto de Pesquisas Agropecuárias do. Su1. Pelotas, Circ. 48: 76 pp.

MOTA, F.S.; M.I.C. BEIRSDORF; M.J.C. COSTA; W.A. MOTTA E S.L. WESTPHALEN, 1974. Zoneamento Agroclimático do Rio Grande do Sul e Santa Catarina. Instituto de Pesquisas Agropecuārias do Sul e Secretaria da Agricultura - RS., Pelotas, 121 pp. 
OLIVEIRA, A.C., 1976. Comparação de Alguns Métodos de Determinação da Estabilidade em Plantas Cultivadas. Brasilia, Universidade de Brasỉlia, 64 pp. (Dissertação de Mestrado).

OSÓRIO, E.A.; J.C.S. MOREIRA; E.C. da SILVA e M.L. SILVA, 1974 . Es tudos de Adaptação de Cultivares de Trigo no Rio Grande do Sul. I. Adaptação Regional das Cultivares Precoces. Pesquisa Agropecuāria Brasileira. Rio de Janeiro, Sērie Agron., 9: 151-154.

PARODA, R.S. e J.D. HAYES, 1971. An Investigation of Genotype-Envi ronment Interactions for Rate of Ear Emergence in Spring Barley. Heredity. Londres, 26: 157-175.

PASCALE, A.J. e F.S. MOTA, 1966. Aspectos Bioclimáticos da Cultura do Trigo no Rio Grande do Sul. Pesquisa Agropecuāria Brasileira. Rio de Janeiro, 1: 123-140.

PIMENTEL GOMES, F., 1976. Curso de Estatistica Experimental. 6a. Ed., Piracicaba, Livraria Nobel, 430 pp.

ROSITO, C., 1974. Interação Genótipo por Locais em Trigo no Rio Grande do Sul. Piracicaba, ESALQ/USP. $61 \mathrm{pp.} \mathrm{(Dissertação} \mathrm{de}$ Mestrado).

SAMUEL, D.J.A.; J. HILL; E.L. BREESE e A. DAVIES, 1970. Assessing and Predicting Environmental Response in Lolizm perenne. Journal. of Agricultural Science. Cambridge, 75: 1-9.

SCHLEHUBER, A.M.; J.C.S. MOREIRA e M.C. MEDEIROS, 1970. Estudo de Correlações Simples Entre Ensaios de Variedades de Trigo Realiza dos no Rio Grande do Sul. Pesquisa Agropecuāria Brasileira. Rio de Janeiro, Série Agron. 5: 235-241. 
SEAL, H.L., 1964. Multivariate Statistical Analysis for Biologists. Londres, Methuen, 209 pp.

SEIF, E.; J.C. EVANS e L.N. BALAAM, 1979. A Multivariate Procedure for Classifying Environments According to Their Interaction With Genotypes. Australian Journal of Agricultural Research. Melbour ne, 30: 1021-1026.

SHUKLA, G.K., 1972. Some Statistical Aspects of Partitioning Genotype-Environmental Components of Variability. Heredity. Londres, 28: $237-245$.

SILVA, W.J.; L.T. MIRANDA e G.P. VIEGAS, 1963. Estimativa do Progresso Genético Médio em Ensaios de Cultivares de Milho. Bragantia. Campinas, 22: 247-258.

SOKAL, R.R. e C.D. MICHENER, 1958. A Statistical Method for Evaluating Systematic Relationship. University of Kansas Bulletin. Kan sas, 38: 1409-1438.

SOKAL, R.R., 1961. Distance as a Measure of Taxonomy Similarity. Sistematic Zoology, 10: 70-79.

SNEATH, P.H.A. e R.R. SOKAL, 1973. Principles of Numerical Taxonomy. San Francisco, W.H. Freeman, 573 n n.

TAI, G.C.C., 1971. Genotype Stability Analysis and Its Application to Potato Regional Trials. Crop Science. Madison, 11: 184-190.

TAI, G.C.C., 1975. Analysis of Genotype-Environment Interactions Based on the Method of Path Coefficient Analysis. Canadian Journal. of Genetics and Cytology. Ottawa, 17: 141-149. 
TAI, G.C.C., 1979. Analysis of Genotype-Environment Interactions of Potato Yield. Crop Science. Madison, 19: 434-438.

WISHART, D., 1978. CLUSTAN-User Manual. 3a. ed. Edinburgh University, 99 pp. (Inter University Research Councils Series, Report 47).

WRICKE, G., 1962. Zur Berechning der Okovalenz bei Sommer Weizen und Hafer. Z.F. Pflanzenzuchtung, 52: 127-138.

WRIGHT, S., 1921. Correlation and Causation. Journal of Agricultural Research. Washington, 20: 557-585.

WRIGHT, S., 1934. The Method of Path Coefficients. The Annals of the Mathematics Statistics. Baltimore, 5: 161-215.

YATES, F. e W.G. COCHRAN, 1938. The Analysis of Groups of Experiments. Journal of Agricultural Science. Cambridge, 28: 556-580. 
67.

7. APENDICE 
68 .

\section{ANALISE DE VARIATVEIS CANÔNICAS}

Considere-se várias amostras de $\mathrm{N}$ observações p-variadas, as quais deseja-se comparar, ou melhor, $\underline{h}$ universos p-varia dos normalmente distribuídos representados pelas amostras. 0 método que se desenvolve aqui é devido a BARTLETT (1938). De modo análogo à análise de componentes principais, o primeiro univerșo é represen tado por um aglomerado de pontos num espaço de p' dimensões, centrado em um ponto caracterizado por um vetor $\mu^{(1)} \in$ disperso em torno desse ponto em uma forma elipsoidal caracterizada pela matriz de variância e covariância $\Sigma^{(1)}$.

Usando-se as mesmas $\mathrm{p}$ variáveis, o segundo universo é representado nesse espaço de $\mathrm{p}$ dimensões por um segundo aglomera do de pontos, o qual sobrepoem-se ao primeiro, a uma maior ou menor extensão. 0 segundo vetor de médias, $\mu^{(2)}$, situa-se a uma distância 
69.

não nula de $\mu^{(1)}$, e a dispersão do aglomerado, medida por $\Sigma^{(2)}$, pode ou não diferir daquela do primeiro aglomerado.

Raciocínio semelhante é aplicado aos outros h-2 universos $\mathrm{p}$ variados. Uma vez assumido que as $\mathrm{p}$ variáveis são normalmente distribuỉdas, o conjunto de pontos de um universo qualquer pas sa a ser representado pelo vetor $\mu^{(l)}$ e matriz $\Sigma^{(l)}(l=1,2, \ldots, h) .0$ objetivo é, assim, obter uma idéia clara das mütuas posições e orientações destes aglomerados.

Considere-se, então, o conjunto de espaços amostratrados de $\mathrm{p}$ dimensões dos $\underline{h}$ universos. Desde que as matrizes de variância e covariância destes universos são supostas homogêneas, pode-se representar as diferenças entre os vetores de média destes $\underline{h}$ universos por um modelo da forma

$$
\underset{(N \times p)}{X}=\underset{(N \times h)}{Z_{1}} \underset{(h \times p)}{B}+\underset{(N \times p)}{E}
$$

Note-se que $\underline{h}$ linhas de $\underline{B}$ são necessārias para explicar (i) a média geral do conjunto amostral $\underline{N}$, onde $N=N_{1}+N_{2}+\ldots+N_{h}$, e (ii) as h-l diferenças entre as médias dos $\underline{h}$ diferentes universos. A matriz de variância e covariância (dos erros) de cada amostra p varia da é $\Sigma_{\Omega}$, e seu valor comum para os $\underline{\mathrm{h}}$ universos é estimado por

$$
\hat{\Sigma}_{\Omega}=(\mathrm{N}-\mathrm{h})^{-1}\left[\sum_{\ell=1}^{\mathrm{h}}\left(\mathrm{N}_{\ell}-1\right) \hat{\Sigma}^{(l)}\right] .
$$


70.

$$
\begin{gathered}
\text { o objetivo è derivar uma transformação } \\
y=C x,
\end{gathered}
$$

a qual evidenciarà as diferenças entre as médias dos $\underline{h}$ universos, atravēs de suas amostras.

Agora, suponha-se que o modelo representado por (1) é substituỉdo por um modelo no qual a matriz B foi degenerada em uma simples linha de $\beta_{s}^{\prime}$ representando as $p$ mëdias de todos os $\mathrm{N}_{s}^{\prime}$. Pode-se representar a matriz de variância e covariância estimada desse modelo como $\hat{\Sigma}_{w}$. 0 interesse então reside na matriz de variância e covariância da diferença entre os modelos $\Omega$ e w, a qual mede a va riabilidade entre os $\underline{h}$ grupos. Sua estimativa é dada por

$$
\left[(N-1) \sum_{w}-(N-h) \hat{\Sigma}_{\Omega}\right] /(h-1),
$$

a qual representar-se-ā como $\bar{E}$.

$\mathrm{Na}$ anâlise de componentes principais considera-se uma transformação

$$
\mathrm{y}=\mathrm{Ax},
$$

tal que o primeiro eixo é inclinado ao longo da direção da máxima variabilidade entre as $\mathrm{N}$ observações de $\mathrm{p}$ dimensões. Então, um segundo eixo, ortogonal ao primeiro, é inclinado na direção da próxima maior variabilidade, e assim sucessivamente. 0 procedimento $\overrightarrow{\mathrm{e}}$ considerado determinando os componentes de $a_{1}^{\prime}$ (primeira linha de A), tal que maximize a variância da primeira variāve1 transformada, 
denominada $a_{1}^{\prime} x$. Essa variância é $a_{1}^{\prime} \Sigma_{a_{1}}$ e será maximizada, sujeita a $a_{1}^{\prime} a_{1}=1$. Então, chega-se à conclusão de que os elementos do autove tor $a_{1}^{\prime}$ podem ser obtidos das $p$ equações

$$
a_{1}^{\prime} \Sigma=\lambda_{1} a_{1}^{\prime}
$$

onde $\lambda_{1} \bar{e}$ o maior autovalor de

$$
|\Sigma-\lambda I|=0
$$

Esse processo pode então ser repetido para $a_{2}^{\prime}$, correspondendo ao se gundo maior autovalor $\lambda_{2}$, e assim sucessivamente,

Pode-se expressar o conjunto de maximizações na forma matricial, dizendo que se deseja maximizar a matriz de variância e covariância

$$
A \sum A^{\prime}=1
$$

sujeita a

$$
\mathrm{AA}^{\prime}=\mathrm{I},
$$

e que os elementos de A foram então determinados' como soluções das $\mathrm{p}$ equações

$$
\mathrm{A} \Sigma=\Lambda \mathrm{A},
$$

onde os elementos da matriz diagonal A são obtidos como as p raízes da equação

$$
|\Sigma-\lambda I|=0
$$


Embora não se possa pensar em termos de elipsóides de variação absoluta, e seu maior e menor eixos, o presente problema é, contudo, bastante semelhante.

Deseja-se que o primeiro eixo transformado seja in-

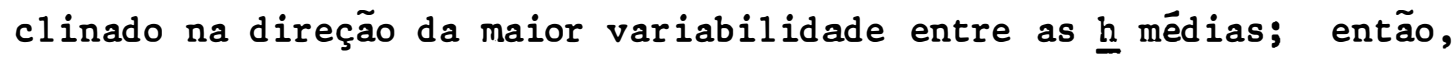
o segundo eixo, ortogonal ao primeiro, é inclinado na direção da prō xima maior variabilidade, e assim sucessivamente. E, enquanto na anālise de componentes principais operou-se com uma matriz de variân cia e covariância $\Sigma$, de dimensões $\mathrm{p} \times \mathrm{p}$, agora utiliza-se uma matriz de variância e covariância $E$, de dimensões $\mathrm{p} \times \mathrm{p}$.

A matriz de transformação $C_{9}$ de (3), tem, então, uma primeira linha $c_{1}^{\prime}$, a qual maximiza a variância entre de $y_{1}$, denomina da

$$
c_{1}^{\prime} E c_{1}
$$

Uma vez que essa maximização conduz a infinitos elementos para $e_{1}^{\prime}$, deve-se impor restrições na matriz de transformação. Estabelece-se, assim, que as variáveis y serão não correlacionadas e de variâncias unitárias. Mas a matriz de variância e covariância da transformação (3) é C $\Sigma_{\Omega} C^{\prime}$ e se está, assim, fazendo a maximização de (4), sujẹ ta a

$$
c_{1}^{1} \sum_{\Omega} c_{1}=1
$$

As exigências já mencionadas para a primeira linha de C podem ser estendidas à segunda, terceira, ... 1inhas, tal que se 
pode finalmente colocar o problema na forma matricial, como segue: Maximizar a matriz de variância e covariância entre

sujeita a

$$
\text { C } \Sigma_{\Omega} C^{\prime}=I
$$

\section{Agora pode-se escrever (5)' na forma}

$$
\left(\mathrm{C} \Sigma_{\Omega}^{1 / 2}\right)\left(\Sigma_{\Omega}^{1 / 2} \mathrm{C}^{\prime}\right)=\left(\mathrm{C} \Sigma_{\Omega}^{1 / 2}\right) \quad\left(\mathrm{C} \Sigma_{\Omega}^{1 / 2}\right)^{\prime}=\mathrm{I}
$$

e fazendo

$$
\text { C } \Sigma_{\Omega}^{1 / 2}=F,
$$

isto é o mesmo que fazer

$$
F F^{\prime}=I \text {. }
$$

Com essa notação, (4)' fica

$$
\text { (C } \left.\Sigma_{\Omega}^{1 / 2}\right) \Sigma_{\Omega}^{-1 / 2} E \Sigma_{\Omega}^{-1 / 2}\left(C \Sigma_{\Omega}^{1 / 2}\right)^{\prime}=F\left(\Sigma_{\Omega}^{-1 / 2} E \Sigma_{\Omega}^{-1 / 2}\right) F^{\prime} \text {. }
$$

A maximização de (7) sujeita a (6) está agora de acordo com a maximização de uma matriz $A \sum A^{\prime}$ sujeita a $A A^{\prime}=I$.

0 procedimento $\bar{e}$, então, como segue. Encontra-se pri meiro as raỉzes $v_{1}>v_{2}>v_{3}>\ldots$ da equação polinomial de p-ésimo grau

$$
\left|\Sigma_{\Omega}^{-1 / 2} E \Sigma_{\Omega}^{-1 / 2}-\mathrm{v} I\right|=0
$$


e, então, determina-se os $p$ elementos de $f_{i}^{\prime}$, i-ésima linha de $F$, provenientes das $\mathrm{p}$ equações

$$
f_{i}^{\prime} \Sigma_{\Omega}^{-1 / 2} E \Sigma_{\Omega}^{-1 / 2}=v_{i} f_{i}^{\prime},
$$

suplementada pela relação

$$
f_{i}^{\prime} f_{i}=1
$$

Finalmente, encontra-se os $p$ elementos de $c_{i}^{\prime}$ das $p$ relações

$$
c_{i}^{\prime} \Sigma_{\Omega}^{1 / 2}=f_{i}^{\prime}
$$

Embora isto seja formalmente correto pode-se visuali zar algumas destas passagens substituindo (11) em (9) e (10). Isso quer dizer que, tendo encontrado as raizes $v_{1}, v_{2} \ldots$ de (8), obtem-se os $p$ elementos de $c^{\prime}$, provenientes de

$$
c_{i}^{\prime} E \Sigma_{\Omega}^{-1 / 2}=v_{i} c_{i}^{\prime} \Sigma_{\Omega}^{1 / 2}
$$

ou melhor, pela pōs-multiplicação por $\Sigma_{\Omega}^{1 / 2}$, de

$$
c_{i}^{\prime} E=v_{i} c_{i}^{!} \Sigma_{\Omega}
$$

suplementado por

$$
c_{i}^{\prime} \Sigma_{\Omega} c_{i}=1
$$

Quando se considera o aspecto de computação, não é necessārio fazer as divisões finais por $\mathrm{N}-\mathrm{h}$ ou $\mathrm{h}-1$ a $\mathrm{fim}$ de obter $\hat{\Sigma}_{\Omega}$ ou $\bar{E}$, respectivamente. Chamando de $\mathrm{H}$ a matriz das somas de qua- 
75.

drados e produtos entre os $\underline{h}$ grupos, e E a correspondente matriz den tro, tem-se

$$
H=(h-1) \hat{E} \quad \text { e } \quad E=(N-h) \hat{\Sigma}_{\Omega}
$$

e (8) fica, depois da divisão de cada elemento de suas duas matrizes $(p \times p)$ por $(N-h) /(h-1)$,

$$
\mid E^{-1 / 2} \text { H } E^{-1 / 2}-\phi I \mid=0 \text {, }
$$

onde

$$
\phi=\frac{\mathrm{h}-1}{\mathrm{~N}-\mathrm{h}} \mathrm{v}
$$

Então (9)' e (10)' ficam

$$
c_{i}^{\prime} H=\phi_{i} c_{i}^{!} E
$$

e

$$
c_{i}^{\prime} E \quad c_{i}=N-h \quad
$$

respectivamente.

As $\underline{p}$ raỉzes de (8) somente são distinguíveis quando $\mathrm{p} \leq \mathrm{h}-1$. Quando $\mathrm{p}>\mathrm{h}-1$ existem $(\mathrm{p}-\mathrm{h}-1)$ raizes nulas $\mathrm{e} \mathrm{h}-1$ outras raỉzes distinguiveis. E muito importante lembrar isso quando (8)" é tratado como uma equação em $\phi$.

A expressão (8)" pode ser colocada na forma

$$
\left|H E^{-1}-\phi I\right|=0,
$$


e uma vez os autovalores $\phi$ tenham sido calculados, os elementos de

$$
C=\left[\begin{array}{c}
c_{1}^{\prime} \\
c_{2}^{\prime} \\
\cdots \\
c_{p}^{\prime}
\end{array}\right]
$$

onde o autovetor $c_{i}^{\prime} \bar{e}$ um vetor linha de $p$ elementos podem ser ge rados como soluções das equações

$$
\left(H E^{-1}-\phi_{i} I\right) c_{i}=0,
$$

o que corresponde à solução de (9)" e (10)". 